\title{
Isolation and Functional Characterization of SOC1-like Genes in Prunus mume
}

\author{
Yushu Li \\ Beijing Key Laboratory of Ornamental Germplasm Innovation and Molecular Breeding, National \\ Engineering Research Center for Floriculture, Beijing Laboratory of Urban and Rural Ecological \\ Environment, College of Landscape Architecture, Beijing Forestry University, Beijing 100083, \\ China; and Beijing Vocational College of Agriculture, Beijing 102442, China
}

Zongda Xu, Weiru Yang, Tangren Cheng, Jia Wang, and Qixiang Zhang ${ }^{1}$ Beijing Key Laboratory of Ornamental Germplasm Innovation and Molecular Breeding, National Engineering Research Center for Floriculture, Beijing Laboratory of Urban and Rural Ecological Environment, College of Landscape Architecture, Beijing Forestry University, Beijing 100083, China

\begin{abstract}
Additional INDEX words. mei, flowering time, identification, MADS-box gene
Abstract. The MADS-box gene SOC1/TM3 (suppressor of overexpression of constans 1/tomato MADS-box gene 3) integrates multiple flowering signals to regulate the transition from vegetative to reproductive development in arabidopsis (Arabidopsis thaliana). Although $S O C 1$-like genes have been isolated from a wide range of plant species, their orthologs are not well characterized in mei (Prunus mume), an important ornamental and fruit plant in east Asia. To better understand the molecular regulation of flower development in mei, we isolated and characterized three putative orthologs of arabidopsis SOC1, including PmSOC1-1, PmSOC1-2, and PmSOC1-3. The phylogenetic tree revealed that these genes fall into different subgroups within the $S O C 1$-like gene group, suggesting distinct functions. PmSOC1-1 and PmSOC1-3 were mainly expressed in vegetative organs and at low expression levels in floral parts of the plants, whereas PmSOC1-2 was expressed only in vegetative organs. Furthermore, the expression level decreased significantly during flower bud differentiation development, suggesting a role for these genes in the transition from the vegetative to the reproductive phase. Overexpression of PmSOC1-1, PmSOC1-2, and PmSOC1-3 in arabidopsis caused early flowering. Early flowering also increased expression levels of four other flowering promoters, agamous-like 24 (AGL24), leafy $(L F Y)$, apetala 1 (AP1), and fruitfull $(F U L)$. Moreover, the overexpression of PmSOC1-1 and PmSOC1-2 resulted in a range of floral phenotype changes such as sepals into leaf-like structures, petal color into green, and petal into filament-like structures. These results suggested that the genes PmSOC1-1, PmSOC1-2, and PmSOC1-3 play an evolutionarily conserved role in promoting flowering in mei, and may have distinct roles during flower development. Our findings will help elucidate the molecular mechanisms involved in the transition from vegetative to reproductive development in mei.
\end{abstract}

The floral transition is one of the most dramatic developmental switches in the life cycle of flowering plants. The transition from vegetative to reproductive phase is regulated by a complex genetic network that monitors the developmental cues and environmental signals. Six genetic pathways, namely, photoperiod, vernalization, autonomous, gibberellin (GA), ambient temperature, and age control flowering in the model plant arabidopsis (Fornara et al., 2010; Simpson and Dean, 2002; Srikanth and Schmid, 2011). These six pathways converge to regulate a small number of "floral integrator genes," including $S O C 1$ and flowering locus T $(F T)$, which mediate other regulators such as the floral meristem identity gene, $L F Y$, to determine the formation of floral meristems (Borner et al., 2000; Lee et al., 2000; Liu et al., 2008; Moon et al., 2003; Samach et al., 2000; Wang et al., 2009).

In the photoperiod pathway, constans $(\mathrm{CO})$, which plays a central role and mediates the circadian clock, activates $S O C 1$ mainly through $F T$ (Valverde et al., 2004; Wigge et al., 2005; Yanovsky and Kay, 2002; Yoo et al., 2005). Conversely, in the

Received for publication 29 Dec. 2015. Accepted for publication 30 Mar. 2016. The research was supported by the Ministry of Science and Technology (Grant No. 2013AA102607) and the Special Fund for Beijing Common Construction Project. ${ }^{1}$ Corresponding author. E-mail: zqxbjfu@126.com. vernalization and autonomous pathways, flowering locus $\mathrm{C}$ $(F L C)$ acts as a floral transition repressor, and suppresses the expression of $S O C l$ by directly binding to the promoters of SOCl (Michaels and Amasino, 1999; Searle et al., 2006). In the GA pathway, GA regulates SOCl at the shoot apex to influence phase transition. Moreover, the soc1 null mutants demonstrate a reduced sensitivity to GA, and overexpression of SOC1 rescues the nonflowering phenotype of gal-3 in shortday (SD) conditions (Lee and Lee, 2010). SOC1 is also regulated by an age-dependent mechanism involving SPL9 and microRNA156. SPL9, as a miRNA156-targeted squamosa promoter binding protein-like $(S P L)$ transcription factor, shows low expression at the early seedling stage. However, SPL9 subsequently increases its expression from the vegetative phase until and through the transition of flowering, independent of the photoperiod, and binds to the first intron of SOCl. Together, these data indicate that SPL9 is a positive age-related regulator of $S O C 1$ independent of FT/flowering locus D (FD) (Wang et al., 2009). Recent studies have revealed other interesting functions of $S O C 1$. For example, $S O C 1$ directly represses $\mathrm{C}$ repeat/dehydration-responsive element (CRT/DRE)binding factors $(C B F s)$ to negatively regulate the cold response pathway, whereas overexpression of $C B F s$ increases the $F L C$ transcript level and causes delayed flowering (Seo et al., 2009). 
SOC1 belongs to the TM3 clade of MADS-box genes, which possess a highly conserved DNA-binding domain and is conserved among angiosperms including both monocotyledons and dicotyledons (Cseke et al., 2003; Ferrario et al., 2004; Lee et al., 2000, 2004, 2008; Nakamura et al., 2005). Expression analyses showed that SOC1 is mainly expressed in developing leaves and shoot apical meristems and its expression level increases with the developmental age in arabidopsis (Borner et al., 2000; Lee et al., 2000; Samach et al., 2000; Wang et al., 2009). Arabidopsis contains six AtSOC1-like genes, but only a few have been studied in detail (Becker and Theissen, 2003). Some of these genes, such as AtAGL14, are expressed only in roots, whereas AtAGL19 is also expressed in rosette leaves and seedlings except roots (Schönrock et al., 2006). AtAGL71 is expressed in arabidopsis seedlings (Ma et al., 2005), whereas AtAGL72 has not been explored further. Both AtAGL71 and AtAGL72 were investigated in the comprehensive arabidopsis MADS domain protein-protein interaction mapping assay (de Folter et al., 2005). AtAGL42 is mainly expressed in arabidopsis roots, where its expression can be used as a marker for the quiescent center (Nawy et al., 2005).

So far, SOC1-like genes in a wide range of plant species have been isolated, such as UNSHAVEN (UNS) [petunia (Petunia hybrida)], GhSOC1 [gerbera (Gerbera hybrida)], OsSOC1 [rice (Oryza sativa)], DOSOC1 [dendrobium orchid (Dendrobium)], GmSOC1 [soybean (Glycine max)], EgrSOC1 [lisianthus (Eustoma grandiflorum)], ZmmADS1 [maize (Zea mays)], TrcMADS1 [trillium (Trillium camtschatcense)], ClSOC1 [chrysanthemum (Chrysanthemum lavandulifolium)], HvSOC1 [barley (Hordeum vulgare)], PTM5 [poplar (Populus tremuloides)], ETL [tasmanian bluegum (Eucalyptus globulus)], and VvMADS8 [grape (Vitis vinifera)] (Cseke et al., 2003; Decroocq et al., 1999; Ding et al., 2013; Ferrario et al., 2004; Fu et al., 2013; Heuer et al., 2001; Lee et al., 2004; Na et al., 2013; Nakamura et al., 2005; Nakano et al., 2011; Papaefthimiou et al., 2012; Ruokolainen et al., 2011; Sreekantan and Thomas, 2006). Nevertheless, very few of these genes are functionally characterized in woody perennials. Flowering in woody perennials differs significantly from herbaceous species such as arabidopsis in having distinct juvenile and adult periods during development. First, most woody perennials have a longer juvenile phase, which lasts for several years, during which time no flowering occurs. This is a great disadvantage for fruit breeding. Second, when attaining the adult stage, flowering in most woody trees (especially fruit trees) is spread over two growing seasons. During the first season, meristems with a potential to differentiate flowers are initiated in the lateral buds of developing shoots. By autumn, the second season, these buds have ceased growth and become dormant (Lang, 1987). A certain amount of chilling accumulation or treatment with dormancy-breaking chemicals is needed to release dormancy (Faust et al., 1997; Horvath et al., 2003). Recent studies suggest that the application of SOC1 orthologs has a potential to reduce the juvenile phase and promote floral transition in woody plants. In grape, the overexpression of SOC1 ortholog $(V v M A D S 8)$ in arabidopsis promotes flowering, indicating that this gene functions as a promoter of flowering (Sreekantan and Thomas, 2006). Ectopic expression of CSSL1, a SOC1-like gene in sweet orange (Citrus sinensis), causes early flowering in arabidopsis wild-type ecotypes Columbia and C24. The expression of CsSL1 functionally complements the late flowering phenotype of the socl mutant; it exhibits an expression pattern similar to arabidopsis SOC1 (Tan and Swain, 2007). In the woody perennial, rose gum (Eucalyptus grandis), the overexpression of SOC1-like genes (EgrMADS 3 and EgrMADS 4) in the arabidopsis ecotype Columbia, accelerate flowering time under SD conditions, implicating their role as floral activators (Watson and Brill, 2004). Therefore, further functional characterization of SOC1-like genes in woody plants is required to facilitate the breeding of woody plants.

Mei, a rosaceous woody perennial tree, has been cultivated in China and other east Asian countries for over 3000 years for its ornamental and economic value (Chen, 1996). As an earlyblooming garden ornamental, mei possesses many conspicuous ornamental characteristics such as colorful corollas, pleasant fragrance, and various types of flowers (Chen, 1996; Sun et al., 2013). Moreover, mei is also an important commercial fruit tree due to its flavorful fruit. These unique properties endow mei with a high cultural and commercial value in China and elsewhere. There is an urgent need to cultivate new mei cultivars with enhanced ornamental and nutritional value, suitable for consumer needs. However, mei takes a long time to reach its reproductive age, which reduces its breeding efficiency and, thus, its yield. Therefore, it is essential to study the expression patterns of floral integrator genes in mei, understand its flowering mechanisms, and promote its molecular breeding. Our ultimate objective is to use this knowledge to develop practical applications in mei such as artificial induction of flowering and reduction of the juvenile period.

The completed sequenced genome of mei (Zhang et al., 2012) enabled us to isolate and characterize three SOC1-like genes (denoted PmSOC1-1-PmSOC1-3) from mei. We analyzed the phylogenetic relationships and expression patterns of these genes, and their effects on the phenotypes of transgenic arabidopsis ectopically expressing them.

\section{Materials and Methods}

Plant materials and growth conditions. Mei cultivar Changrui Lve was used in this study [the wild species 'Zang mei' in Tongmai town (Tibet, China) was the genotype used for mei genome sequencing]. 5-year-old adult trees were grown in Beijing Jiufeng International Plum Blossom Garden (Beijing, China), and 1-month-old seedlings were grown in a greenhouse at 16 to $25^{\circ} \mathrm{C}$ with $60 \%$ relative humidity under a $12-\mathrm{h}$ light/dark cycle. The wild-type arabidopsis ecotype Columbia-0 (Col-0), 35S::PmSOC1-1, 35S::PmSOC1-2, and 35S::PmSOC1-3 transgenic plants of the same ecotype were grown in soil at $22 \pm 1{ }^{\circ} \mathrm{C}$ under long-day (LD) (16 h light/8 h dark) or SD (8 h light/16 h dark) conditions. In all cases, samples were collected and immediately frozen in liquid nitrogen and stored at $-80{ }^{\circ} \mathrm{C}$ until RNA extraction. Samples were collected from three plants to provide three biological replicates.

Total RNA EXTRACTION AND COMPlementary DNA SYNTHESIS. Total RNA was extracted from leaf buds using TRIzol reagent (Invitrogen, Carlsbad, CA) following the manufacturer's instructions. Potentially contaminating genomic DNA was eliminated by treatment with RNase-free DNase I according to the manufacturer's instructions (Promega, Madison, WI). First strand complementary DNA (cDNA) synthesis was carried out from $2 \mu \mathrm{g}$ of total RNA using the TIANScript First Strand cDNA Synthesis Kit (Tiangen, Beijing, China) according to the manufacturer's protocol.

Gene CLONING. Mei genome sequences were downloaded from the mei genome project (Zhang et al., 2012). To identify 
SOC1-like genes in mei, the arabidopsis gene AtSOC1 (accession no. AT2G45660.1) protein sequences was downloaded from The Arabidopsis Information Resource (Rhee et al., 2003) and used as initial query to perform BLASTP searches against the mei genome database. Three SOC1-like genes, named PmSOC1-1, PmSOC1-2, and PmSOC1-3, were identified in mei. For obtaining the complete cDNA sequences of PmSOC1-1, PmSOC1-2, and PmSOC1-3, combinations of primers were designed based on the nucleotide sequence from mei genome sequences (Supplemental Table 1). Polymerase chain reaction (PCR) assays were performed in a total volume of $25 \mu \mathrm{L}$ containing $1 \mu \mathrm{L}$ cDNA, $0.8 \mathrm{U}$ Taq DNA polymerase (Promega), $0.5 \mu \mathrm{M}$ of each primer, $1 \times$ PCR buffer (Promega), $1.5 \mathrm{~mm}$ $\mathrm{MgCl} 2$, and $0.2 \mathrm{~mm}$ dNTP mix (Promega). The PCR conditions were as follows: $94{ }^{\circ} \mathrm{C}$ for $5 \mathrm{~min}, 30$ cycles of $94{ }^{\circ} \mathrm{C}$ denaturation for $30 \mathrm{~s}, 57{ }^{\circ} \mathrm{C}$ annealing for $30 \mathrm{~s}$, and $72{ }^{\circ} \mathrm{C}$ extension for $1 \mathrm{~min}$, with a final extension at $72{ }^{\circ} \mathrm{C}$ for $7 \mathrm{~min}$. The amplified products were separated in 1.0\% agarose gels, cloned into the pMD18-T vector (Takara Biotechnology, Dalian, China) following manufacturer's instructions and subsequently sequenced in both directions. The full-length cDNA sequence of PmSOC1-2 and PmSOC1-3 were deposited at GenBank (accession no.s KP938964 and KP938965), whereas PmSOC1-1 was found to have $100 \%$ identity with the sequence JF806632.1 in GenBank.

Sequence alignment and phylogenetic analysis. The protein sequences of the SOC1-like genes aligned in this study were retrieved from the National Center for Biotechnology Information database and plant genome database [Phytozome (Goodstein et al., 2012)]. Multiple sequence alignments were performed using DNAMAN version 5.2.2 and Clustal W (Thompson et al., 1994). Proteomics Server of the Expert Protein Analysis System of the Swiss Institute of Bioinformatics (Gasteiger et al., 2003) was used to predict the conserved protein domain sequences of PmSOC1-1, PmSOC1-2, and PmSOC1-3. A phylogenetic tree was generated using Molecular Evolutionary Genetics Analysis (MEGA) version 5.1 (Tamura et al., 2011) and the neighbor-joining method with the following parameters: Poisson correction, complete deletion, and bootstrap (1000 replicates).

ParafFin Sectioning AND IDENTIFICATION OF FLORAL BUd DIFFERENTIATION STAGE. To analyze the expression patterns of PmSOC1-like genes during mei floral bud differentiation, we used paraffin sections to identify floral bud differentiation stage. For paraffin sectioning, floral bud development was categorized into eight stages (predifferentiation stage, flower primordium differentiation stage, sepal differentiation stage, petal differentiation stage, stamen differentiation stage, pistil differentiation stage, pistil elongation stage, and ovule and anther formation stage). Floral buds from predifferentiation stage to ovule and anther formation stage were collected and fixed with formalin-acetic acid-alcohol fixative (70\% ethanol, $5 \%$ glacial acetic acid, 5\% formaldehyde) by vacuum infiltration. The samples were then dehydrated in an ethanol series before being embedded in paraffin. Vertical sections were cut using a microtome (RM2235; Leica, Wetzlar, Germany). The sections were stained in safranin and fast green staining solution successively and photographed using a microscope (BX53; Olympus, Tokyo, Japan).

REAL-TIME QUANTITATIVE REVERSE TRANSCRIPTION-PCR. The tissue-specific and developmental expression patterns of PmSOC1-1, PmSOC1-2, and PmSOC1-3, were investigated by real-time quantitative reverse transcription PCR (qRTPCR). For the analysis of the spatial localization patterns of PmSOC1-1, PmSOC1-2, and PmSOC1-3 in various organs, young unfolded leaves, mature expanded leaves, stems, leaf buds, floral buds, fully opened floral organs (sepals, petals, stamens, and pistils), seeds, young fruit ( $\approx 45 \mathrm{~d}$ after full bloom, $\approx 10 \mathrm{~mm}$ diameter), and mature fruit $(\approx 95 \mathrm{~d}$ after full bloom, $\approx 30 \mathrm{~mm}$ diameter) of adult trees, and roots, stems, and leaves of 1-month-old seedlings were sampled. For the analysis of PmSOC1-1, PmSOC1-2, and PmSOC1-3 in the floral bud at different developmental stages, two samples of floral buds that were similar were collected weekly from June to Dec. 2013. One sample was used to identify floral bud differentiation stage by paraffin sections, and the other was frozen in liquid nitrogen and stored at $-80^{\circ} \mathrm{C}$ until RNA extraction.

qRT-PCR was performed using the PikoReal real-time PCR system (Thermo Fisher Scientific, Wilmington, DE). Each $20-\mu \mathrm{L}$ quantitative RT-PCR mixture contained $1 \mu \mathrm{L}$ of diluted cDNA, $200 \mathrm{~nm}$ of each primer, and $10 \mu \mathrm{L}$ of SYBR Premix Ex Taq II (Takara Biotechnology). The following conditions were used: $30 \mathrm{~s}$ at $95^{\circ} \mathrm{C}, 40$ cycles of $5 \mathrm{~s}$ at $95^{\circ} \mathrm{C}$, and $30 \mathrm{~s}$ at $60^{\circ} \mathrm{C}$. All qRT-PCR reactions were carried out in biological and technical triplicates, and a nontemplate control was also included in each run. PCR reaction efficiency for each primer pair was determined by a standard curve generated with a cDNA serial dilution. The relative expression levels were calculated using the $2^{-\Delta \Delta \mathrm{Ct}}$ method with the protein phosphatase $2 \mathrm{~A}$ $(P P 2 A)$ gene of mei as the internal control gene (Wang et al., 2014). Relevant primers were designed using Primer Express 3 software (version 0.4.0; PE Applied Biosystems, Foster, CA) to amplify products between 150 and 300 base pairs (bp) in size and their sequences are shown in Supplemental Table 1. The reverse primer used for analyzing gene expression was carefully designed on the $3^{\prime}$ exon-exon junction of the open reading frame (ORF).

VECTOR CONSTRUCTION AND PLANT TRANSFORMATION. The $B g l$ II-BstE II fragment of PmSOC1-1, PmSOC1-2, and PmSOC1-3 were generated by PCR with specific primers (Supplemental Table 1). The fragments were separately cloned into the pMD18-T (Takara Biotechnology) vector and confirmed by sequencing. After digestion with restriction enzymes Bgl II and BstE II, the fragments were cloned into the same sites of the pCAMBIA1304 vector under the control of CaMV 35S promoter. 35S::PmSOC1-1, 35S::PmSOC1-2, and 35S::PmSOC1-3 constructs were transformed separately into wild-type arabidopsis plants ecotype Col-0 using the floral-dip method according to Clough and Bent (Clough and Bent, 1998) with Agrobacterium tumefaciens strain EHA105. The seeds of transgenic arabidopsis plants were selected on Murashige and Skoog medium containing $50 \mathrm{mg} \cdot \mathrm{L}^{-1}$ kanamycin at $4{ }^{\circ} \mathrm{C}$ for $2 \mathrm{~d}$, and then were transferred to the greenhouse under LD or SD conditions at $22 \pm 1{ }^{\circ} \mathrm{C}$ for $10 \mathrm{~d}$. Subsequently, the seedlings were transplanted to soil. As a control reference, untransformed control seeds were planted at the same time on the above medium minus kanamycin. The homozygous T3 plants were used for gene function analyses.

GENE EXPRESSION ANALYSIS AND PHENOTYPIC OBSERVATION OF TRANSGENIC PLANTS. Rosette leaves from transgenic and wildtype arabidopsis plants were collected for RT-PCR and qRTPCR verification. The CaMV $35 \mathrm{~S}$ promoter-specific forward primer and SOC1-like (PmSOC1-1, PmSOC1-2, and PmSOC1-3) gene-specific reverse primers were designed (Supplemental 
Table 1). For analysis of the expression levels of $L F Y, A P 1$, $A G L 24$, and FUL in the transgenic arabidopsis lines, 6-, 12-, and 16-d-old transgenic seedlings were sampled for qRT-PCR assay. The TUB2 gene of arabidopsis was used as an internal control; and the gene-specific primers of $T U B 2, L F Y, A P 1$, $A G L 24$, and FUL are shown in Supplemental Table 1. Flowering time was scored by counting the days from sowing to the opening of the first flower. Furthermore, the number of rosette leaves was counted when the first flower opened. According to a completely randomized design, wild-type and T3 transgenic plants ( $>20$ per line) were used for flowering-time and floralphenotype recording. Statistical analyses were performed with SPSS statistics software (version 16.0; IBM Corp., Armonk, $N Y$ ). Student's $t$ test was used to detect the significance of flowering time differences.

\section{Results}

IDENTIFICATION OF SOC1-LIKE GENES IN MEI. The search for the homologs of arabidopsis AtSOC1 protein sequences from the mei genome (Zhang et al., 2012) identified three PmSOC1-like genes (PmSOC1-1, PmSOC1-2, and PmSOC1-3). Each PmSOC1-like gene has a single long ORF encoding a putative protein of 214, 217, and 219 amino acids, respectively (Supplemental Fig. 1). The predicted molecular masses of PmSOC1-1, PmSOC1-2, and PmSOC1-3 are 24.6, 24.91, and 24.95 kDa, respectively; and the estimated isoelectric points are 9.46, 8.68, and 9.05. All three genes belong to the type II MADS-box proteins, as they harbor the strongly conserved MADS domain, a less-conserved $\mathrm{K}$ domain, and a highly variable $\mathrm{C}$-terminal region (Supplemental Fig. 1). Structural analysis between the fulllength cDNA and genomic DNA sequence revealed that PmSOC1-1 and PmSOC1-2 contained eight exons and seven introns, whereas PmSOC1-3 consisted of seven exons and six introns. All locus regions of these genes displayed the consensus splice sites GT and AG. The start codon of PmSOC1-3 is located in the first exon, whereas those of PmSOC1-1 and PmSOC1-2 are in the second exon (Supplemental Fig. 2). The lengths of first, third, fourth, fifth, and sixth exons within the coding region are the same in different plant species, and are: 182, 62, 100, 42, and 42 bp, respectively (Supplemental Fig. 2).

The sequence analysis using deduced amino acid sequences of PmSOC1-like genes revealed that PmSOC1-1 shares a 68\% sequence identity with arabidopsis SOC1. It shares an even higher sequence identity with SOC1 homolog genes in Rosaceae Prunus plants such as PaSOC1 [apricot (Prunus armeniaca); 98\% identity], PpSOC1 [peach (Prunus persica); 95\% identity], and PsSOC1 [plum (Prunus salicina); 95\% identity]. However, PmSOC1-2 and PmSOC1-3 share a lower sequence identity with SOC1 orthologs in Rosaceae Prunus plants, for example, PmSOC1-2 showed 59\%, 57\%, and 58\% and PmSOC1-3 showed 55\%, 54\%, and 55\% identity to PaSOC1 (apricot), PpSOC1 (peach), and PsSOC1 (plum), respectively (Supplemental Fig. 1). Moreover, alignment of the deduced amino acid sequence of PmSOC1-like and other SOC1-like proteins revealed that they contain a well-conserved SOC1 motif at their C-terminus (Supplemental Fig. 1). This motif is only specific in the SOC1/TM3 clade of MADS-box genes from gymnosperms and angiosperms (Nakamura et al., 2005; Vandenbussche et al., 2003).

We constructed a phylogenetic tree to determine the evolutionary relationship between PmSOC1-like proteins and other
SOC1-like proteins (Fig. 1). The tree showed that three PmSOC1-like genes clustered in a dicotyledonous group which mostly included SOC1 and its orthologs. On the other hand, the other SOC1 orthologs such as ZmSOC1 from maize and TaSOC1 from wheat (Triticum aestivum) clustered in a monocotyledonous group. PmSOC1-1 was closely related to arabidopsis SOC1, along with SOC1-like members from some woody perennial species. PmSOC1-2 and PmSOC1-3 formed distinct subgroups, which was more closely related to other less-studied arabidopsis SOC1-like genes. PmSOC1-2 was grouped in phylogeny with AtAGL71, AtAGL72, and AtAGL42, whereas PmSOC1-3 was grouped with AtAGL14 and AtAGL19. Remarkably, each of the three PmSOC1-like genes, PmSOC11, PmSOC1-2, and PmSOC1-3, had their corresponding orthologous gene in peach (Fig. 1). Moreover, the distribution pattern of three SOC1-like genes in mei and peach are similar, that is, in each species, two genes were located on one chromosome, and the other gene was located on another chromosome (Wells et al., 2015; Xu et al., 2014). To be specific, in mei, PmSOC1-1 and PmSOC1-2 were located on chromosome 5, PmSOC1-3 was located on chromosome 7; in peach, PpMADS22 and PpMADS60 were located on chromosome 2, and PpMADS64 was located on chromosome 5 . This similarity suggests that functions of SOC1like genes in flowering are conserved in mei and peach.

TeMPORAL AND SPATIAL EXPRESSION PATTERNS OF SOC1-LIKE GENES. We used qRT-PCR to study the spatiotemporal expression patterns of the three PmSOC1-like genes (PmSOC1-1, PmSOC1-2, and PmSOC1-3) in different organs of mei (Fig. 2). The results showed that in the adult tree, expression levels of the three PmSOC1-like genes were high in the leaf buds, flower buds, stems, and leaves, but relatively low in the reproductive organs (Fig. 2). In 1-month-old seedlings, PmSOC1-1 and PmSOC1-3 were expressed in roots, stems, and leaves, whereas PmSOC1-2 was only expressed weakly in roots (Fig. 2). To determine whether the function of the three PmSOC1-like genes in transition of blossoms is as important as that of AtSOC1 in Arabidopsis, we identified eight critical stages of mei bud differentiation (Fig. 3A) using the paraffin method. We detected the expression patterns of three PmSOC1-like genes during each differentiation stage (Fig. 3B). Throughout the bud differentiation process, all three genes presented a downward trend in terms of expression levels. They showed the highest expression profile in the undifferentiated stage (S1 stage), after which the expression levels of PmSOC1-2 gradually decreased, and PmSOC1-1 and PmSOC1-3 expression profiles decreased less gradually. Once the flower bud differentiation commenced, expression levels started to decrease, suggesting that these three genes, especially PmSOC1-2, may play an important role in mei bud differentiation.

OVEREXPRESSION OF SOC1-LIKE GENES IN ARABIDOPSIS CAUSES EARLY FLOWERING. We analyzed the expression profiles of PmSOC1-like genes in transgenic arabidopsis using RT-PCR and qRT-PCR. Each PmSOC1-like gene was expressed in six transgenic arabidopsis lines (Fig. 4A). Real-time quantitative results showed that exogenous genes from different transgenic lines displayed various expression levels (Fig. 4B). The transgenic phenotype of 35S::PmSOC1-3 was comparatively consistent, whereas the transgenic phenotypes of 35S::PmSOC1-1 and 35S::PmSOC1-2 exhibited both strong and weak phenotypes in terms of flowering time and the extent of phenotypic variation. The transgenic lines no. 1, no. 6, and no. 9 of 35S:: PmSOC1-1 transgenic line were strong phenotypes, whereas no. 13 , no. 18 , and no. 24 were weak phenotypes. The transgenic 


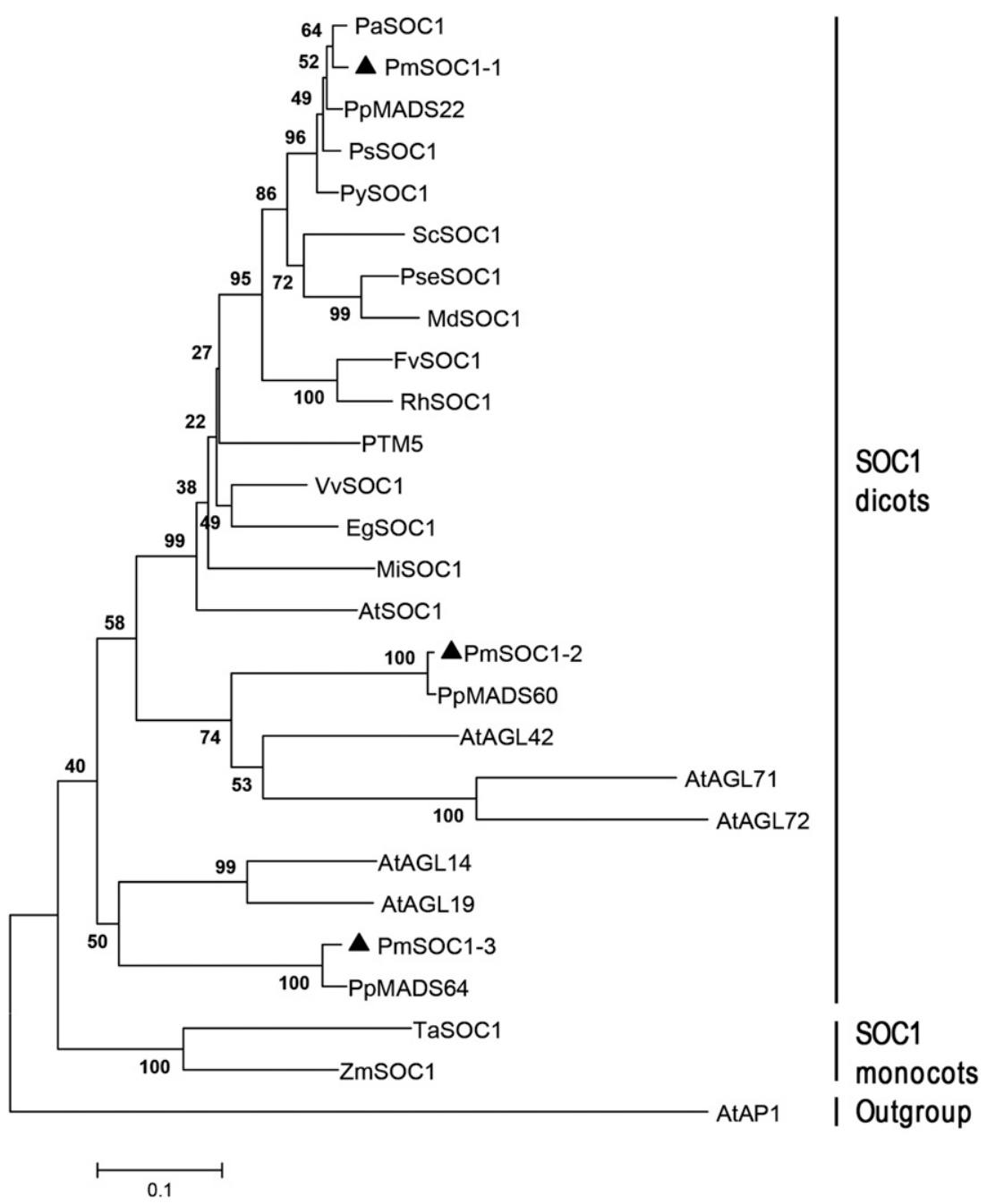

Fig. 1. Phylogenetic analyses of PmSOC1-like proteins from different plant species. The phylogenetic tree was generated by the neighbor-joining method after bootstrapping. Numbers at nodes indicate bootstrap values (1000 replicates). Dicots and monocots were in the same branch separately. A nonSOC1-like protein, APETALA1 (AP1) from Arabidopsis thaliana was chosen as the outgroup. Accession numbers are as follows: Prunus armeniaca [PaSOC1 (AGD88524)], Prunus mume [PmSOC1-1 (AEQ20229), PmSOC1-2 (KP938964), PmSOC1-3 (KP938965)], Prunus salicina [PsSOC1 (AGD88523)], Prunus ×yedoensis [PySOC1 (AEO20233)], Spiraea cantoniensis [ScSOC1 (AEO20234)], Photinia serratifolia [PseSOC1 (AEO20232)], Malus domestica [MdSOC1 (BAI49495)], Fragaria vesca [FvSOC1 (AEO20231)], Rosa hybrida [RhSOC1 (AEO20230)], Populus tremuloides [PTM5 (AF377868)], Vitis vinifera [VvSOC1 (ACZ26527)], Eucalyptus grandis [EgSOC1 (XP_010053874)], Mangifera indica [MiSOC1 (ADX97324)], A. thaliana [AtSOC1 (AEC10583), AtAGL42 (AED97572), AtAGL71 (AED96138), AtAGL72 (AED96136), AtAGL14 (AEE83062), AtAGL19 (AEE84684), AtAP1 (CAA78909)], Triticum aestivum [TaSOC1 (BAF56968)], and Zea mays [ZmSOC1 (ACG32892)]. Prunus persica (PpMADS22 is positioned on the peach genome map on scaffold 2: 20,600,270...20,606,939 reverse; PpMADS60 is positioned on the peach genome map on scaffold 2: 28,315,091...28,320,984 reverse; and PpMADS64 is positioned on the peach genome map on scaffold 5: $9,862,429 \ldots 9,867,768$ reverse).

lines no. 5 , no. 8 , and no. 10 of $35 \mathrm{~S}:: P m S O C 1-2$ were strong phenotypes and no. 14 , no. 19 , and no. 28 were weak phenotypes.

The transgenic lines showing a strong phenotype of $35 \mathrm{~S}:$ : PmSOC1-1 flowered early (5 rosette leaves) under LD conditions as compared with the wild-type arabidopsis lines (13 rosette leaves) (Fig. 5IA). 35S::PmSOC1-2 transgenic lines with strong phenotype showed the earliest flowering time among all transgenic lines (Table 1). Individual 35S::PmSOC1-2 transgenic lines flowered even at three-rosette-leaves stage (Fig. 5IIA). The weak phenotype of $35 \mathrm{~S}:$ P $\mathrm{PSOC} 1-2$ could also flower with an average of six rosette leaves. Under LD conditions, 35S::PmSOC1-3 transgenic lines need 32.4 $34.5 \mathrm{~d}$ to flower. This flowering time is slightly shorter than that of the wild-type lines, which takes $\approx 37.3 \mathrm{~d}$ on average to flower (Table 1 ). The above results suggest all three PmSOC1like genes can cause early flowering irrespective of their potencies.

OVEREXPRESSION OF PMSOC1-1 AND PMSOC1-2 IN ARABIDOPSIS AFFECTS FLORAL ORGAN DEVELOPMENT AND PLANT MORPHOGENESIS. Besides advanced flowering (Fig. 5IIIA-IIIG), the 35S::PmSOC1-3 transgenic lines were not much different from the wild-type arabidopsis (Fig. 5IVA-IVG). Analysis of qRT-PCR showed that PmSOC1-3 transgenic lines had different expression profiles (Fig. 4B), suggesting that $35 \mathrm{~S}:: P m S O C 1-3$ was stably expressed in transgenic lines.

When inducing early flowering in arabidopsis, 35S::PmSOC1-1 and 35S::PmSOC1-2 transgenic lines showed weak and strong phenotypes in flowers, colors, and plant architecture. Except for the more significant petal refinement in 35S::PmSOC1-2 transgenic lines, other variations in weak phenotypes of 35S::PmSOC1-1 and 35S::PmSOC1-2 transgenic lines remained the same as compared with the wild-type line. These included filamentous petals, upright petal entablature, which can barely spread into a cross (Fig. 5IB and IIB), elongated pistils, which extended to outer perianth (Fig. 5IC and IIC), leaf-like sepals (Fig. 5ID, IE, IID, and IIE), and petals and sepals not dropping off till the silique elongation period (Fig. 5IF and IIF). Their strong phenotypes were manifested in different variations. Besides all the variations showed in weak phenotypes, strong phenotypes of $35 \mathrm{~S}:: P m S O C 1-1$ transgenic lines, there have been variations of petal color turning green as compared with the wild type (Fig. 5IH and II), whereas strong phenotypes of 35S::PmSOC1-2 exhibited significant changes in plant morphogenesis, such as all lateral branches showing horizontal growth (Fig. 5IIG) so that the plant architecture of arabidopsis completely changed. Moreover, 2-4 flowers connately formed terminal flower (TF) in part of the terminal inflorescence in 35S::PmSOC1-2 strong phenotypes. The number of floral in TF was indefinite, and those flowers usually bloomed first (Fig. 5IIH and III).

Moreover, all strong phenotypes of 35S::PmSOC1-1 and 35S::PmSOC1-2 transgenic lines showed relatively high expression levels in qRT-PCR. For example, no.5 35S::PmSOC1-2 transgenic line flowered early, and exhibited the most significant phenotypic variation with the highest expression level of transgenes in qRT-PCR (Fig. 4B), indicating a positive correlation between expression abundance of transgenes and phenotypic variation of transgenic plants. 


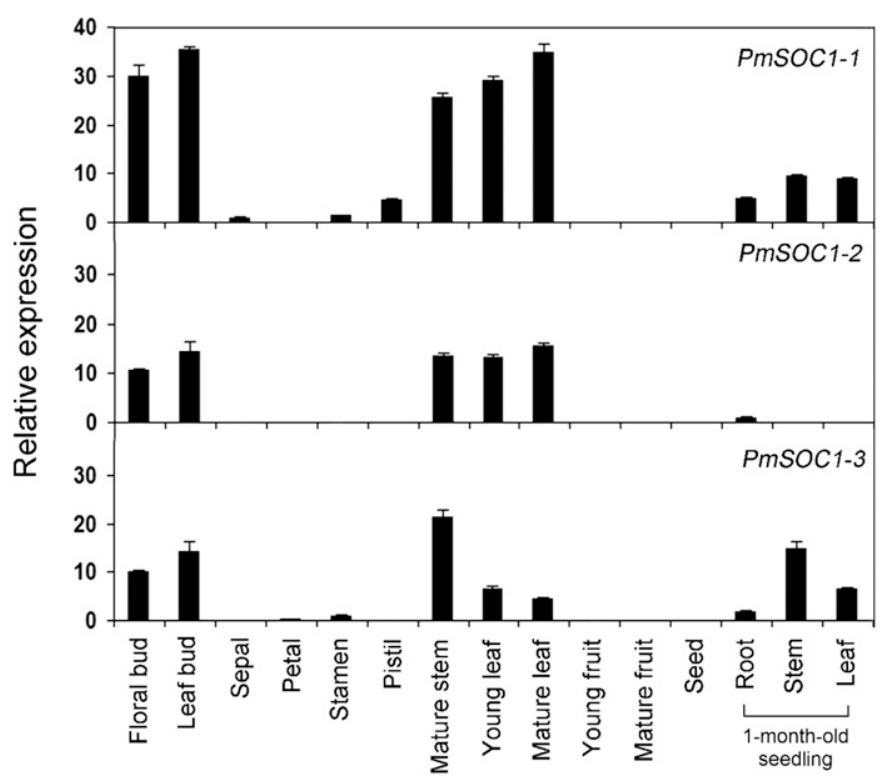

Fig. 2. Expression analyses of PmSOC1-like genes in different organs of Prunus mume by real-time quantitative reverse transcription polymerase chain reaction. The level of expression was normalized to $P$. mume $P P 2 A$ gene. Error bars represent standard errors for three replicate reactions.

PMSOC1-LIKE GENES CAN INDUCE THE EXPRESSION OF FLORAL MERISTEM IDENTITY GENES IN TRANSGENIC ARABIDOPSIS PLANTS. SOC1 gene can integrate multiple flowering signaling pathways and promote flowering by upregulating its downstream floral meristem characteristic gene (Lee and Lee, 2010; Lee et al., 2008). We studied the expression profiles of $L F Y, A P 1$, $A G L 24$, and $F U L$ in strong-phenotype 6-, 12-, and 16-d-old transgenic arabidopsis seedlings, to verify whether the early flowering phenotype is caused by the upregulation of downstream floral meristem genes induced by PmSOC1-like genes.

According to our results, $L F Y$ maintained a significantly higher expression level in 35S::PmSOC1-2 transgenic arabidopsis line than the other two transgenic lines $(35 \mathrm{~S}:$ : PmSOC1-1 and 35S::PmSOC1-3) (Fig. 6A). The expression profile of $A P l$ showed a consistent trend with $L F Y$ (Fig. 6B). However, the expression profiles of $A G L 24$ that is functionally similar to $S O C 1$, and $F U L$, which promote initiation and development of flowering (Liu et al., 2008; Michaels et al., 2003; Yu et al., 2002), showed a progressive rise along with the growth and development of plants (Fig. 6C and D).

\section{Discussion}

Flowering is a transition stage from vegetative to reproductive growth of plants, and is determined by internal and environmental factors. Woody perennials such as mei need to go through a long period of vegetative growth (juvenile period) before flowering, as compared with herbaceous plants such as arabidopsis. Understanding the flowering transition process in woody perennials is critically important in order to shorten the juvenile period and accelerate the cultivar improvement process. In the MADS-box gene family, the gene SOC1 controls the flowering time. It can integrate a variety of flowering signals and has been intensively studied for years. Although researchers have studied SOC1 in the model plant arabidopsis, there have been few studies of SOC1 homologous genes in woody perennials. In this study, we isolated three SOC1-like genes from mei and examined their expression patterns and functions.

PMSOC1-LIKE GENES BELONG TO THE SOC1/TM3 CLADE OF THE MADS-BOx TRANSCRIPT FACTORS. MADS-box gene is an important class of transcription factors widespread in eukaryotes. It plays an important role in plant growth regulation and signal transduction (Messenguy and Dubois, 2003; Ng and Yanofsky, 2001), especially in floral organ differentiation, flowering time, and related aspects of fruit development and maturation (Irish, 2003).

Phylogenetic analysis showed that MADS-box genes can be divided into two categories in eukaryotes, namely, type I and type II. In plants, the function of type I MADS-box genes remains unknown, and these genes only contain the conserved regions (Nam et al., 2004). The type II MADS-box genes are composed of domains with varying degrees of conservatism, including M (MADS-box), I (intervening), K (keratin), and Cterminal. Thus, it is also called MIKC-type MADS-box (Kaufmann et al., 2005). Dependent on differences of gene sequence and structure, MIKC-type MADS-box genes can be further categorized into MIKC* type and MIKC $^{\mathrm{C}}$ type (Alvarez-Buylla et al., 2000; Henschel et al., 2002). Currently, $\mathrm{MIKC}^{\mathrm{C}}$ is the most known gene, and it has an essential role in plant growth and development. On the basis of the features of gene sequence, structure, and functions, $\mathrm{MIKC}^{\mathrm{C}}$ can be further divided into 13 subfamilies, including $A G$-like, $A G L 2$-like, $A G L 6$-like, $A G L 12$-like, $A G L 15$-like, $A G L 17-$ like, $D E F-G L O$ like, FLC-like, GGM13-like, SQUA-like, STMADS11-like, TM8-like, and SOC1/TM3-like (Becker and Theissen, 2003). In the arabidopsis MADS-box family, the SOC1/TM3 subfamily includes six genes: $A G L 14, A G L 19, A G L 20$ (SOC1), $A G L 42, A G L 71$, and $A G L 72$.

In our study, the three MADS-box genes separated from mei showed high homology with SOC1/TM3 subfamily genes. They have typical MADS-box domain, K-box domain, and a highly conserved motif specific to SOC1 on the C-terminal (Supplemental Fig. 1). These motifs play a significant role in the formation and transcriptional activation of protein complexes (Honma and Goto, 2001; Kramer and Irish, 1999). Therefore, they are included in the SOC1/TM3 subfamily and are named PmSOC1-1, PmSOC1-2, and PmSOC1-3. Within the coding region, all $S O C 1$ orthologs consist of seven exons and six introns with exactly the same lengths of the first, third, fourth, fifth, and sixth exons (Supplemental Fig. 2). However, the total number of exons of those genes is different; for example, there are seven exons in PmSOC1-3, which differs from the eight exons in PmSOC1-1, PmSOC1-2, and AtSOC1. Moreover, the initiation codon of PmSOC1-3 is located in the first exon, whereas those of PmSOC1-1 and PmSOC1-2 are in the second exon. The region between the first exon and the initiation codon might be an important transcriptional regulatory position, because that of some other genes have distinct relationship to gene expression (Clancy and Hannah, 2002; Jeon et al., 2000; Jeong et al., 2006; Mun et al., 2002). Phylogenetic analysis suggested that PmSOC1-1, PmSOC1-2, and PmSOC1-3 genes might be orthologs of arabidopsis SOC1, $A G L 42 / 71 / 72$, and $A G L 14 / 19$, respectively. Previous studies revealed that there was a gene duplication that gave rise to the SOC1 gene and $A G L 42 / 71 / 72$ genes (Dorca-Fornell et al., 2011). Thus, we 

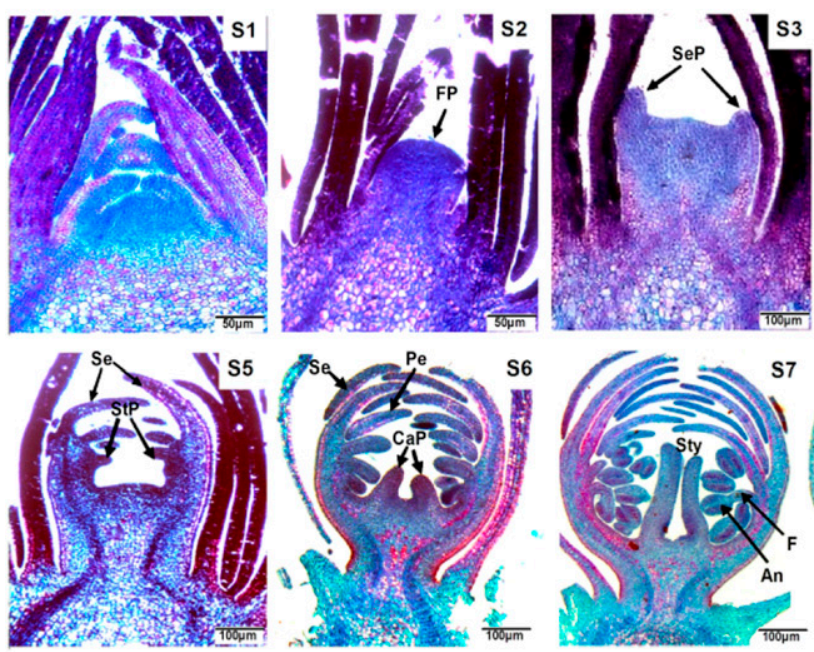
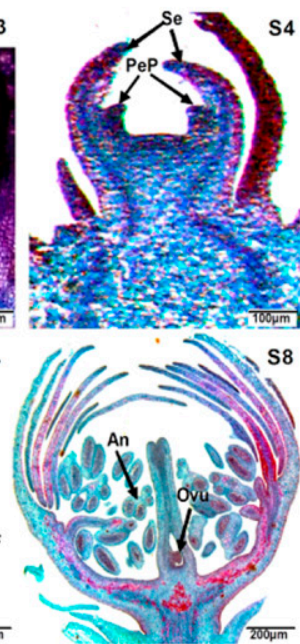

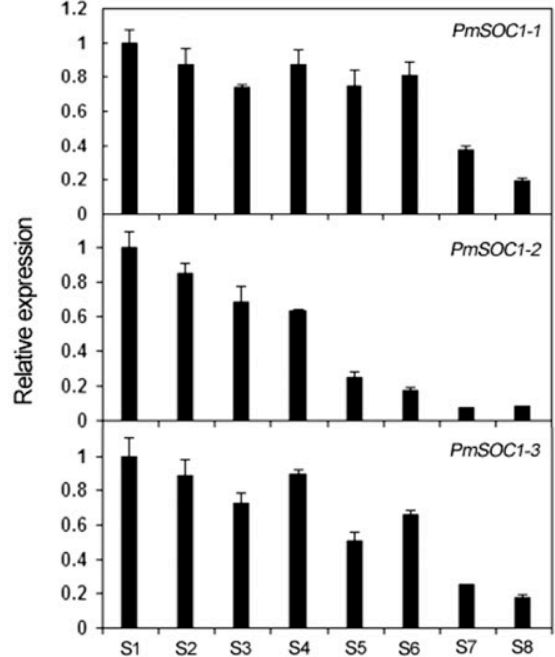

B

A

Fig. 3. Expression analyses of PmSOC1-like genes during Prunus mume floral bud differentiation. (A) Images of paraffin sections of floral bud at different developmental stages. To analyze the timing of floral bud formation, we examined paraffin sections that had been stained with safranin and fast green. Images of representative paraffin sections for floral bud at different developmental stages are shown. $\mathrm{FP}=$ flower primordium, $\mathrm{SeP}=$ sepal primordium, $\mathrm{Se}=$ sepal, $\mathrm{PeP}=$ petal primordium, $\mathrm{StP}=$ stamen primordium, $\mathrm{Pe}=$ petal, $\mathrm{CaP}=$ carpel primordium, $\mathrm{Sty}=$ style, $\mathrm{An}=$ anther, $\mathrm{F}=$ filament, and $\mathrm{Ovu}=\mathrm{ovule} .(\mathbf{B}) \mathrm{Relative}$ expression of PmSOCl-like genes in the floral bud at different developmental stages. The level of expression was normalized to $P$. mume PP $2 A$ gene. The relative expression ratio of each sample is compared with the predifferentiation stage sample, and arbitrarily set to 1 . $\mathrm{S} 1=$ predifferentiation stage, $\mathrm{S} 2=$ flower primordium differentiation stage, $\mathrm{S} 3=$ sepal differentiation stage, $\mathrm{S} 4=$ petal differentiation stage, $\mathrm{S} 5=$ stamen differentiation stage, $\mathrm{S} 6=$ pistil differentiation stage, $\mathrm{S} 7=$ pistil elongation stage, and S8 = ovule and anther formation stage.
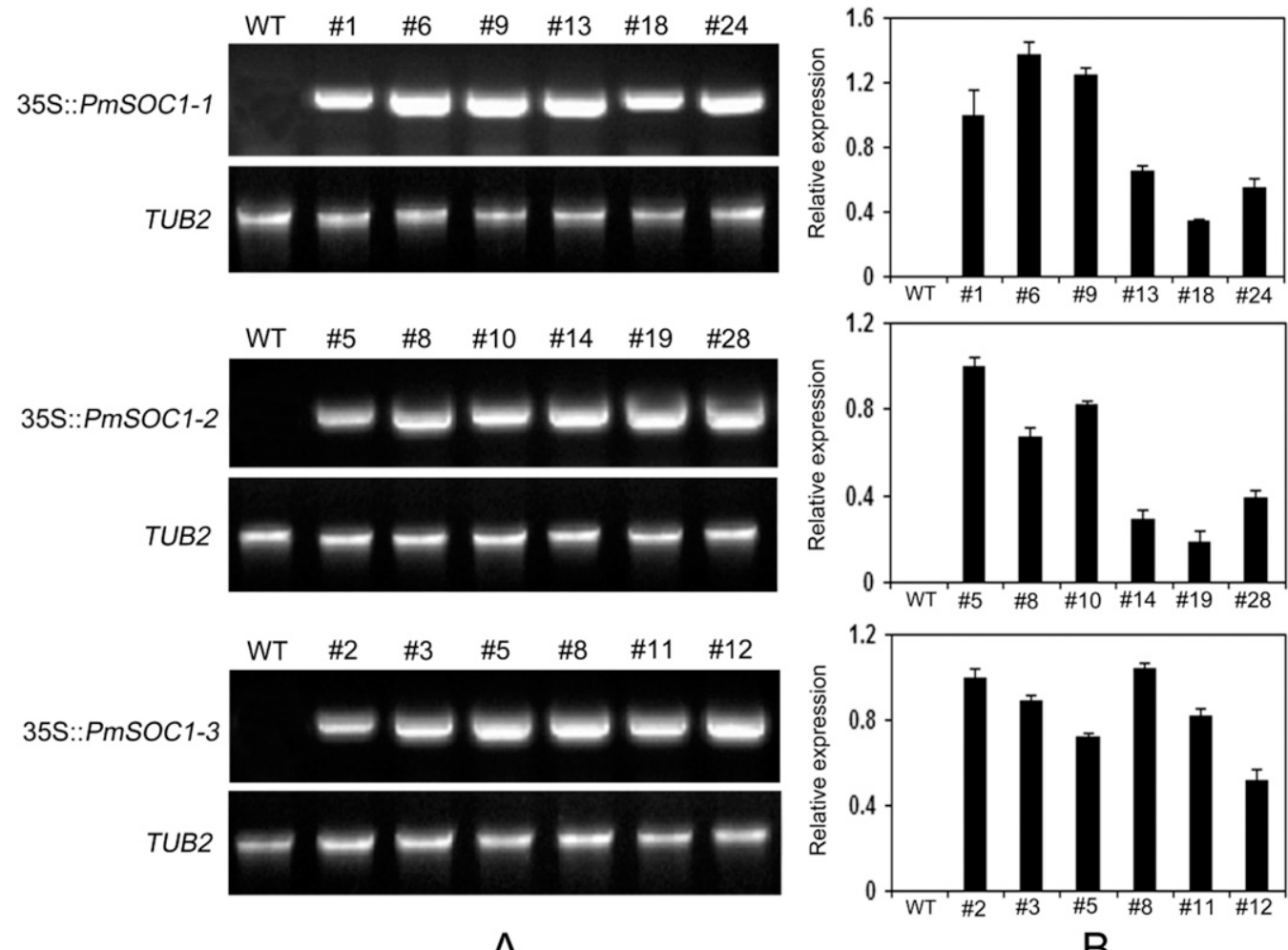

A

B

Fig. 4. Expression analyses of PmSOCl-like genes in transgenic Arabidopsis thaliana. (A) The expression of an exogenous gene detected by reverse transcription polymerase chain reaction (RT-PCR). (B) The relative expression levels of an exogenous gene detected by real-time quantitative RT-PCR.

speculated that three PmSOC1-like genes have identical ancestral origin, but they differentiate during the evolutionary process, and eventually play different roles in development of flowers and vegetative organs of mei. Moreover, comparing with the three genes $(A G L 42 / 71 / 72)$ in arabidopsis, mei and peach have only one ortholog (mei: PmSOC1-2, peach: 


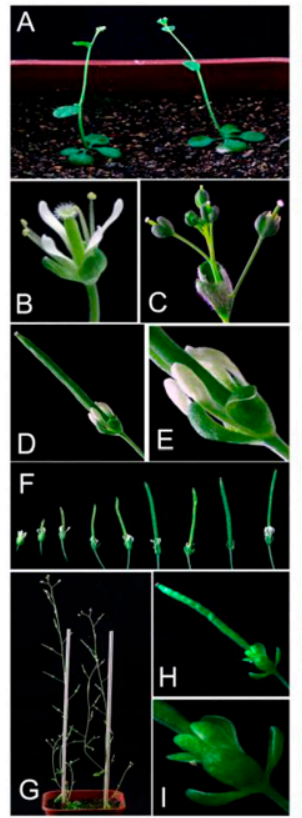

35S::PmSOC1-1 (I)
35S::PmSOC1-2 (II)

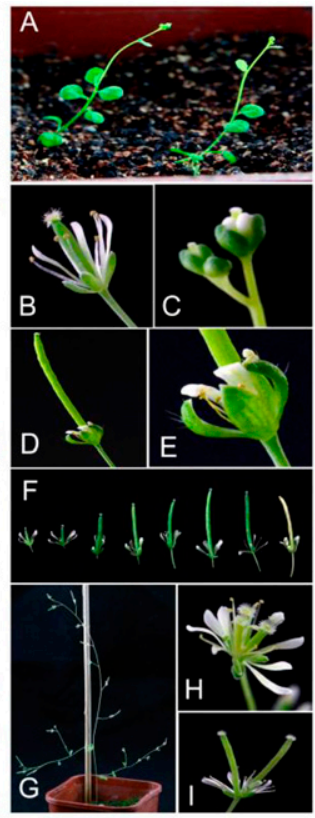

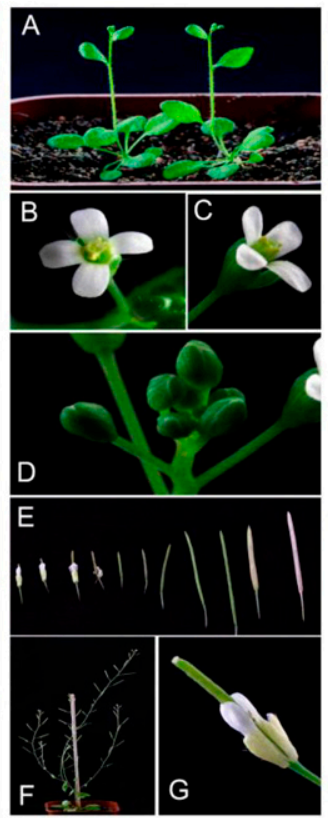

35S::PmSOC1-3 (III)
Fig. 5. Comparison of the phenotypes of wild-type, 35S::PmSOC1-1, 35S::PmSOC1-2, and 35S::PmSOC1-3 transgenic Arabidopsis thaliana. (IA-II) Constitutive expression of $35 \mathrm{~S}::$ PmSOC1-1 transgenic $A$. thaliana plant. (IIA-III) Constitutive expression of $35 \mathrm{~S}:: P m S O C 1-2$ transgenic A. thaliana plant; (IIIA-IIIG) constitutive expression of 35S::PmSOC1-3 transgenic $A$. thaliana plant; (IVA-IVG) wild-type $A$. thaliana plants; (IA, IIA, and IIIA) 35S::PmSOC1-1, 35S::PmSOC1-2, and 35S::PmSOC1-3 transgenic A. thaliana plants, early flowering in comparison with IVA at $30 \mathrm{~d}$ after sowing under long-day conditions; (IB and IIB) flower of 35S::PmSOC1-1 and 35S::PmSOC1-2 transgenic $A$. thaliana, respectively, with petals into filamentlike structures; (IIIB, IIIC, IVB, and IVC) flower from 35S::PmSOC1-3 transgenic and wild-type A. thaliana, respectively, with the normal petal; (IC and IIC) flower of 35S::PmSOC1-1 and 35S::PmSOC1-2 transgenic $A$. thaliana, respectively, with large carpel out of perianth; (IIID and IVD) flower from 35S::PmSOC1-3 transgenic and wild-type $A$. thaliana, respectively, with the normal carpel; (ID, IE, IID, and IIE) flower of 35S::PmSOC1-1 and 35S::PmSOC1-2 transgenic $A$. thaliana, respectively, with sepals into leaf-like structures; (IIIG and IVG) flower from 35S::PmSOC1-3 transgenic and wild-type $A$. thaliana, respectively, with the normal sepals; (IF and IIF) flower of $35 \mathrm{~S}:: P m S O C 1-1$ and $35 \mathrm{~S}:: P m S O C 1-2$ transgenic $A$. thaliana, respectively, with petals and sepals abscission inhibited at silique elongation stage; (IIIE and IVE) flower from 35S::PmSOC1-3 transgenic and wild-type $A$. thaliana, respectively, with all organs falling from green silique at the same development stage with IF and IIF; (IIG) 35S::PmSOC1-2 transgenic A. thaliana plants, horizontal growth of branches in comparison with IG, IIIF, and IVF; (IH and II) flower of 35S::PmSOC1-1 transgenic $A$. thaliana with greenish sepaloid petal; (IIH and III) flower of 35S::PmSOC1-2 transgenic A. thaliana with different morphologies of terminal flowers.

PpMADS60), and AGL42, AGL71, and AGL72 were proved to be redundantly controlling flowering time in arabidopsis (Dorca-Fornell et al., 2011). These data indicated that the duplication and diversity of arabidopsis SOCl-like genes occurred after the divergence of arabidopsis and Prunus.

The EXPRESSION PATTERNS OF PMSOC1-LIKE GENES. So far, MADS-box genes in the SOC1/TM3 clade have been isolated from a wide range of plant species, including dicots, monocots, and gymnosperms. Most of these studies have investigated expression patterns of $S O C 1$-like genes. The expression of EgrMADS3 and EgrMADS4, two SOC1-like genes in the vegetative tissues (particularly apical shoots) of rose gum, was consistent with their probable roles as floral activators in this species (Watson and Brill, 2004). VvMADS8, which is a SOCl-like gene in grape, was most highly expressed in the axillary buds at the time when the inflorescence started to form in these buds, indicating that $V v M A D S 8$ is a gene involved in the timing of flowering (Sreekantan and Thomas, 2006). ClSOC1-1 and ClSOC1-2, which are two SOCl-like genes in chrysanthemum, were mainly expressed in leaves and shoot apices with the highest expression level after $7 \mathrm{~d}$ of $\mathrm{SD}$
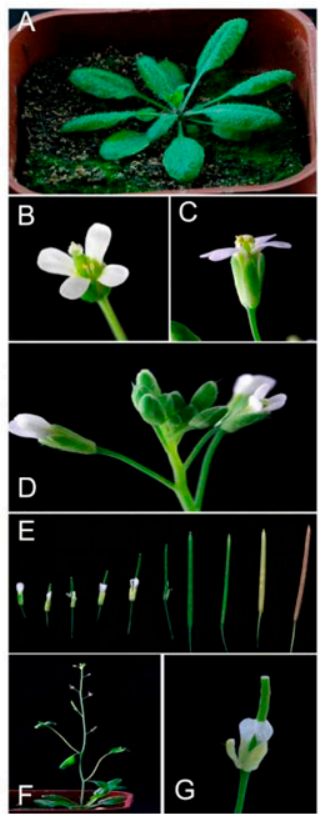

wild type (IV) treatment, suggesting that these two SOCl-like genes might be involved in flower transition (Fu et al., 2013). Soybean GmSOC1-like gene was widely expressed at different levels in most organs with the highest expression in the shoot apex during the transition to flowering (Na et al., 2013). CjMADS15, which is an SOCl-like gene in japanese cedar (Cryptomeria japonica), was expressed in all organs except pollen, and was especially expressed in needles, stems, and strobili (Katahata et al., 2014).

In our study, the expression of PmSOC1-1, PmSOC1-2, and PmSOCl-3 was examined in vegetative and reproductive tissues and during floral bud differentiation development. Three PmSOC1-like genes were mainly expressed in vegetative organs such as leaves, stems, and buds, and at low expression levels in floral parts of the plants (Fig. 3). Furthermore, PmSOC1-1 and PmSOCl-2 were more highly expressed in leaves and stems of adult trees than in 1-month-old seedlings. In arabidopsis, SOC1 expression levels are also gradually increased during vegetative growth (Borner et al., 2000; Lee et al., 2000; Samach et al., 2000; Wang et al., 2009). The different expression levels of PmSOC1-1 and PmSOC12 in leaves and stems of adult and juvenile trees may reflect the maturity of the plants. During floral bud differentiation development, the expression level of PmSOCl-2 was decreased most significantly in three PmSOCl-like genes (Fig. 3B). These results indicated that the three PmSOCl-like genes might imply a general role in the transition from the vegetative to the reproductive phase in mei, especially PmSOC1-2.

Although SOCl-like genes share similar expressions as discussed above, there are studies that uncovered their different expression patterns. Gerbera GhSOC1 was expressed in the inflorescence and organs derived from the inflorescence, but no expression was detected in the vegetative parts (Ruokolainen et al., 2011). Both PTM5 in poplar and DOSOC1 in dendrobium orchid are expressed in vascular tissues, implying that SOCl-like genes could similarly affect the life cycle of many flowering plants (Cseke et al., 2003; Ding et al., 2013). These results suggest that SOC1/TM3-like genes have various expression patterns, implying that the functions of these genes may be more diversified in the complex regulatory network of floral transition.

PMSOC1-3 IS PRINCIPALLY ASSOCIATED WITH FLOWERING INDUCTION, WHEREAS PMSOC1-1 AND PMSOC1-2 ARE ASSOCIATED WITH FLORAL ORGAN DEVELOPMENT AND PLANT MORPHOGENESIS IN ARABIDOPSIS. In arabidopsis flowering process, SOCl was the first gene shown to be upregulated in 
Table 1. Flowering phenotypes of transgenic Arabidopsis thaliana. Twenty transgenic plants of each line and 40 wild-type plants were used for observation.

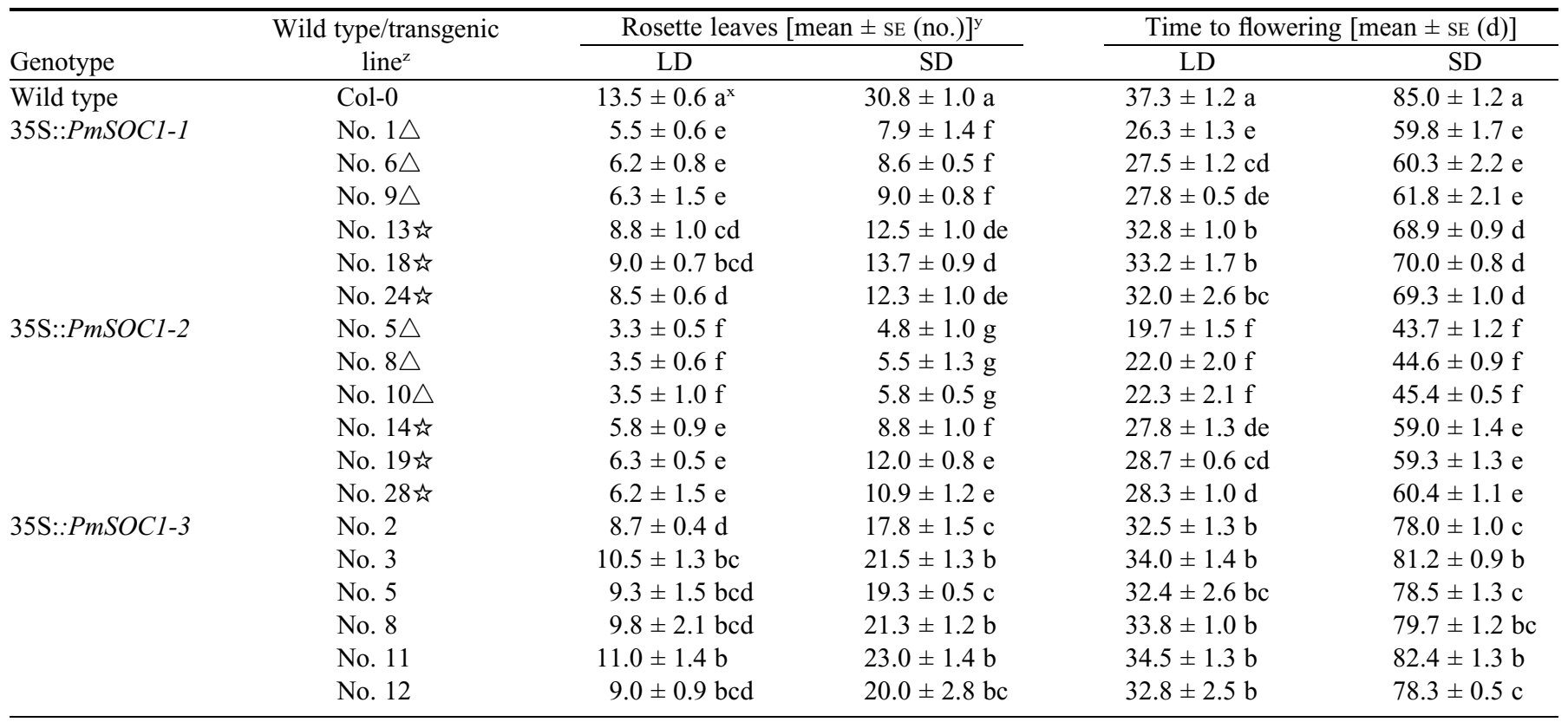

${ }^{\mathrm{z} C o l-0}=$ wild-type $A$. thaliana ecotype Columbia- $0, \triangle=$ strong phenotype, $\bar{\omega}=$ weak phenotype.

${ }^{y} \mathrm{LD}=$ long-day (16-h light/8-h dark) conditions, $\mathrm{SD}=$ short-day (8-h light/16-h dark) conditions.

xDifferent lowercase letters in the same column indicate a significant difference at $P<0.05$ according to Student's $t$ test.

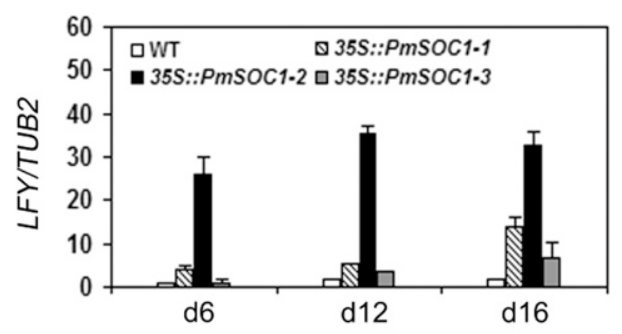

(A)

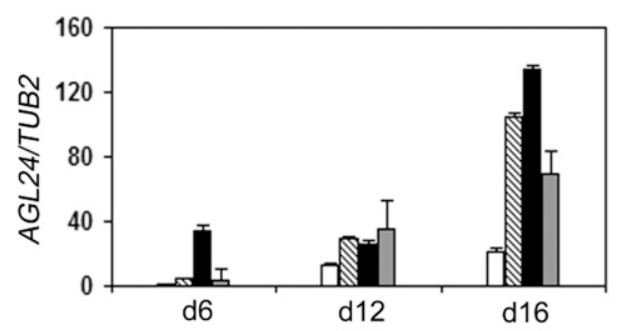

(C)

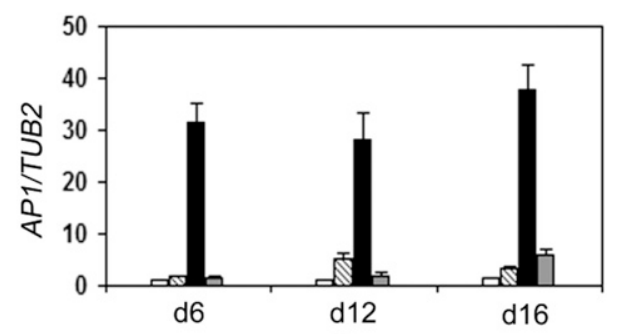

(B)

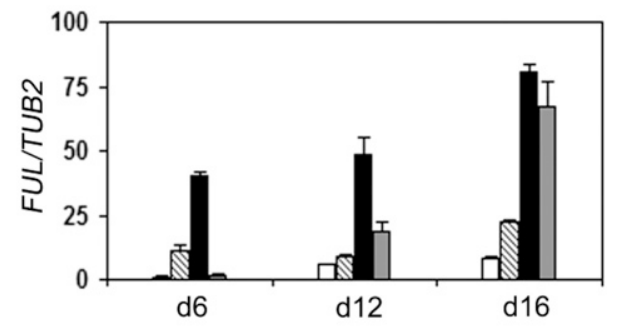

(D)

Fig. 6. Expression analyses of different flowering time genes in transgenic Arabidopsis thaliana seedlings grown for days 6, 12, and 16 in long-day conditions. Relative expression levels were normalized to A. thaliana TUB2 expression. Error bars indicate the standard errors. (A) $L F Y$ expression, (B) $A P 1$ expression, (C) $A G L 24$ expression, and (D) FUL expression.

meristems to promote early flowering. Currently, the overexpression of SOC1 homologous genes identified in other species consistently showed the early flowering phenotype in arabidopsis. These species include ClSOC1-1 and ClSOC1-2 in chrysanthemum ( $\mathrm{Fu}$ et al., 2013), $V v M A D S 8$ in grape (Sreekantan and Thomas, 2006), EgrSOC1 in lisianthus (Nakano et al., 2011), and CsSL1 in sweet orange (Tan and Swain, 2007). The overexpression of GmGAL1 in soybean and DOSOC1 in dendrobium orchid not only enables early flowering in wild-type arabidopsis but also complements part of the late-flowering phenotype in SOC1 mutants (Ding et al., 2013; Zhong et al., 2012). In our study, transgenic arabidopsis lines presented early flowering phenotype under both LD and SD conditions, implying a conserved role of SOC1/ TM3 gene family in promoting flowering.

In many species, SOC1-like genes have shown impacts on flower development, in addition to promoting flowering. Overexpression of AtSOC1 in arabidopsis resulted in greenish sepaloid petal and elongated pistil (Borner et al., 2000). Overexpressed GhSOC1 in gerbera did not promote flowering, but led to changes in petal color and shape (Ruokolainen et al., 2011). Overexpression of UNS from petunia in arabidopsis caused the appearance of trichomes in floral organs, which should originally grow on leaves and stems, and further turned petals into a leaf-like structure (Ferrario et al., 2004). Overexpression of DOSOC1 in dendrobium orchid influenced the normal development of floral organs, causing an unsound perianth on the top flower bud (Ding et al., 2013). Similarly, overexpression of PmSOC1-1 and PmSOC1-2 in arabidopsis resulted in phenotypes such as filamentous petal and leaf-like sepal in our study (Fig. 5). Among them, overexpression of 
PmSOC1-1 led to green petals and elongated pistils, which are consistent with phenotypes generated by overexpression of AtSOC1 (Fig. 5IC and II). These phenotypes indicated that SOCl-like genes can regulate floral development apart from promoting flowering. Interestingly, the overexpression of PmSOC1-2 changed the lateral branch angle of arabidopsis; thus, changing the architecture of arabidopsis (Fig. 5IIG). This phenotype has not yet been reported in any study of overexpression phenotypes of $\mathrm{SOCl}$ in other species. This phenotype suggested that overexpression of SOCl-like genes in mei may influence the expression of branch angle-related genes in arabidopsis, leading to the horizontal growth of branches. To further study the molecular mechanisms of increasing branch angle in transgenic arabidopsis, the expression of branch anglerelated genes should be checked using qRT-PCR.

SOC1 genes promote flowering mainly by upregulating its downstream floral meristem genes. For instance, in the process of flowering development, heterodimers are formed by SOC1 and $A G L 24$, which activates $L F Y$ gene expression, thus promoting flowering (Lee et al., 2008). Similar mechanisms also appear between FUL and SOC1. Studies have found that FUL and $S O C 1$ can form a dimer in the cell nucleus and further bind to $L F Y$ promoter region, thus playing the same role. Therefore, redundancy dimers or higher-order molecular complexes can be formed between SOC1, AGL24, and FUL to ensure the activation of $L F Y$, which subsequently activates other floral meristem genes (Balanzà et al., 2014). Overexpression of ClSOC1 from chrysanthemum and DOSOC1 from dendrobium orchid in arabidopsis can upregulate flowering genes such as $A G L 24$ and $L F Y$ (Ding et al., 2013; Fu et al., 2013). In our study, we used qRT-PCR to detect the downstream genes of SOC1 including $L F Y, A P 1, A G L 24$, and FUL in transgenic arabidopsis. The results showed that the introduction of PmSOCl-like genes led to different degrees of upregulations of $L F Y, A P 1$, $A G L 24$, and $F U L$ at various stages compared with the wild type (Fig. 6). The expression of $A G L 24$ and FUL displayed similar trends: both showed a gradual upward trend (from days 6,12 , and 16 after seed germination) suggesting that dimers may be formed between SOC1 and AGL24 or FUL to activate expression of $L F Y$ to promote flowering (Fig. $6 \mathrm{C}$ and D), and this can be further verified by $L F Y$ expression levels in transgenic arabidopsis (Fig. 6A). 35S::PmSOC1-2 lines, the most notable early flowering ones, also presented the highest expression levels of $L F Y$ and $A P 1$, revealing that the PmSOC1-2 gene may effectively activate $L F Y$ gene expression by interacting with $A G L 24$ and FUL. However, we need more evidence to verify this hypothesis.

In recent years, studies have shown that $S O C 1$ also plays other functions in addition to integrating a variety of signals during the flowering process. For example, single SOCl mutant exhibited late-flowering phenotype, whereas double SOC1FUL mutant showed traits of perennials, such as late flowering time, the formation of aerial rosettes, and repeated transition to vegetative growth. It is analyzed that $S O C 1$ and $F U L$ might have inhibited plant transition from annuals to perennials (Melzer et al., 2008). In poplar, the specific expression of the SOC1 homologous gene PTM5 in vascular tissues suggests its involvement in vascular development (Cseke et al., 2003).

In conclusion, PmSOCl-like genes obtained from mei in this study contain typical MADS-box, K-box domain, and conserved motif, belonging to the SOC1/TM3 subfamily of MADS-box gene family. Phylogenetic analysis showed that
PmSOC1-1 is more closely related to arabidopsis SOC1, PmSOC1-2 is more closely related to $A G L 71, A G L 72$, and $A G L 42$, and PmSOC1-3 is more closely related to $A G L 14$ and $A G L 19$. Through phenotypic analysis of transgenic arabidopsis, it is validated that all three genes promote flowering, of which PmSOC1-2 is the most functionally significant one. In addition to early flowering, PmSOC1-1 and PmSOC1-2 can affect floral organ development. Moreover, overexpression of PmSOCl-2 in transgenic arabidopsis can affect plant architecture, but this function has not been reported in any study of SOCl homologous genes. To conclude, three PmSOCl-like genes have identical ancestral origin and probably diversified their function during evolution. Our results provide a theoretical basis for the use of genetic engineering to shorten mei juvenile period and accelerate the cultivar improvement process. However, further studies on the upstream and downstream regulatory sequences of PmSOC1like genes will provide deeper insights into mei flowering.

\section{Literature Cited}

Alvarez-Buylla, E.R., S. Pelaz, S.J. Liljegren, S.E. Gold, C. Burgeff, G.S. Ditta, L.R. De Pouplana, L. Martínez-Castilla, and M.F. Yanofsky. 2000. An ancestral MADS-box gene duplication occurred before the divergence of plants and animals. Proc. Natl. Acad. Sci. USA 97:5328-5333.

Balanzà, V., I. Martínez-Fernández, and C. Ferrándiz. 2014. Sequential action of FRUITFULL as a modulator of the activity of the floral regulators SVP and SOC1. J. Expt. Bot. 65:1193-1203.

Becker, A. and G. Theissen. 2003. The major clades of MADS-box genes and their role in the development and evolution of flowering plants. Mol. Phylogenet. Evol. 29:464-489.

Borner, R., G. Kampmann, J. Chandler, R. Gleissner, E. Wisman, K. Apel, and S. Melzer. 2000. A MADS domain gene involved in the transition to flowering in Arabidopsis. Plant J. 24:591-599.

Chen, J.Y. 1996. Chinese mei flowers. Hainan Publ. House, Haikou, China. (in Chinese).

Clancy, M. and L.C. Hannah. 2002. Splicing of the maize Sh1 first intron is essential for enhancement of gene expression, and a T-rich motif increases expression without affecting splicing. Plant Physiol. 130:918-929.

Clough, S.J. and A.F. Bent. 1998. Floral dip: A simplified method for Agrobacterium-mediated transformation of Arabidopsis thaliana. Plant J. 16:735-743.

Cseke, L.J., J. Zheng, and G.K. Podila. 2003. Characterization of PTM5 in aspen trees: A MADS-box gene expressed during woody vascular development. Gene 318:55-67.

de Folter, S., R.G. Immink, M. Kieffer, L. Pařenicová, S.R. Henz, D. Weigel, M. Busscher, M. Kooiker, L. Colombo, M.M. Kater, B. Davies, and G.C. Angenent. 2005. Comprehensive interaction map of the Arabidopsis MADS box transcription factors. Plant Cell 17:1424-1433.

Decroocq, V., X. Zhu, M. Kauffman, J. Kyozuka, W.J. Peacock, E.S. Dennis, and D.J. Llewellyn. 1999. A TM3-like MADS-box gene from Eucalyptus expressed in both vegetative and reproductive tissues. Gene 228:155-160.

Ding, L., Y. Wang, and H. Yu. 2013. Overexpression of DOSOC1, an ortholog of Arabidopsis SOC1, promotes flowering in the orchid Dendrobium Chao Parya Smile. Plant Cell Physiol. 54:595-608.

Dorca-Fornell, C., V. Gregis, V. Grandi, G. Coupland, L. Colombo, and M.M. Kater. 2011. The arabidopsis SOC1-like genes AGL42, $A G L 71$ and $A G L 72$ promote flowering in the shoot apical and axillary meristems. Plant J. 67:1006-1017.

Faust, M., A. Erez, L.J. Rowland, S.Y. Wang, and H.A. Norman. 1997. Bud dormancy in perennial fruit trees: Physiological basis for dormancy induction, maintenance, and release. HortScience 32:623-629.

Ferrario, S., J. Busscher, J. Franken, T. Gerats, M. Vandenbussche, G.C. Angenent, and R.G. Immink. 2004. Ectopic expression of the 
petunia MADS box gene UNSHAVEN accelerates flowering and confers leaf-like characteristics to floral organs in a dominantnegative manner. Plant Cell 16:1490-1505.

Fornara, F., A. de Montaigu, and G. Coupland. 2010. SnapShot: Control of flowering in Arabidopsis. Cell 141:550.e1-550.e2.

Fu, J., S. Qi, L. Yang, Y. Dai, and S. Dai. 2013. Characterization of chrysanthemum ClSOC1-1 and ClSOC1-2, homologous genes of SOC1. Plant Mol. Biol. Rpt. 32:740-749.

Gasteiger, E., A. Gattiker, C. Hoogland, I. Ivanyi, R.D. Appel, and A. Bairoch. 2003. ExPASy: The proteomics server for in-depth protein knowledge and analysis. Nucleic Acids Res. 31:3784-3788.

Goodstein, D.M., S. Shu, R. Howson, R. Neupane, R.D. Hayes, J. Fazo, T. Mitros, W. Dirks, U. Hellsten, and N. Putnam. 2012. Phytozome: A comparative platform for green plant genomics. Nucleic Acids Res. 40:D1178-D1186.

Henschel, K., R. Kofuji, M. Hasebe, H. Saedler, T. Münster, and G. Theissen. 2002. Two ancient classes of MIKC-type MADS-box genes are present in the moss Physcomitrella patens. Mol. Biol. Evol. 19:801-814.

Heuer, S., S. Hansen, J. Bantin, R. Brettschneider, E. Kranz, H. Lörz, and T. Dresselhaus. 2001. The maize MADS box gene ZmmADS3 affects node number and spikelet development and is co-expressed with ZmmADS1 during flower development, in egg cells, and early embryogenesis. Plant Physiol. 127:33-45.

Honma, T. and K. Goto. 2001. Complexes of MADS-box proteins are sufficient to convert leaves into floral organs. Nature 409:525529.

Horvath, D.P., J.V. Anderson, W.S. Chao, and M.E. Foley. 2003. Knowing when to grow: Signals regulating bud dormancy. Trends Plant Sci. 8:534-540.

Irish, V.F. 2003. The evolution of floral homeotic gene function. Bioessays 25:637-646.

Jeon, J.S., S. Lee, K.H. Jung, S.H. Jun, C. Kim, and G. An. 2000 Tissue-preferential expression of a rice $\alpha$-tubulin gene, OsTubA1, mediated by the first intron. Plant Physiol. 123:1005-1014.

Jeong, Y.M., J.H. Mun, I. Lee, J.C. Woo, C.B. Hong, and S.G. Kim. 2006. Distinct roles of the first introns on the expression of Arabidopsis profilin gene family members. Plant Physiol. 140:196-209.

Katahata, S-I., N. Futamura, T. Igasaki, and K. Shinohara. 2014. Functional analysis of SOC1-like and AGL6-like MADS-box genes of the gymnosperm Cryptomeria japonica. Tree Genet. Genomes 10:317-327.

Kaufmann, K., R. Melzer, and G. Theissen. 2005. MIKC-type MADSdomain proteins: Structural modularity, protein interactions and network evolution in land plants. Gene 347:183-198.

Kramer, E.M. and V.F. Irish. 1999. Evolution of genetic mechanisms controlling petal development. Nature 399:144-148.

Lang, G.A. 1987. Dormancy: A new universal terminology. HortScience 22:817-820.

Lee, H., S.S. Suh, E. Park, E. Cho, J.H. Ahn, S.G. Kim, J.S. Lee, Y.M. Kwon, and I. Lee. 2000. The AGAMOUS-LIKE 20 MADS domain protein integrates floral inductive pathways in Arabidopsis. Genes Dev. 14:2366-2376.

Lee, J. and I. Lee. 2010. Regulation and function of SOC1, a flowering pathway integrator. J. Expt. Bot. 61:2247-2254.

Lee, J., M. Oh, H. Park, and I. Lee. 2008. SOC1 translocated to the nucleus by interaction with AGL24 directly regulates $L E A F Y$. Plant J. 55:832-843.

Lee, S.Y., J. Kim, J.-J. Han, M.-J. Han, and G.H. An. 2004. Functional analyses of the flowering time gene OSMADS50, the putative SUPPRESSOR OF OVEREXPRESSION OF CO 1/AGAMOUS-LIKE 20 (SOC1/AGL20) ortholog in rice. Plant J. 38:754-764.

Liu, C., H. Chen, H.L. Er, H.M. Soo, P.P. Kumar, J.H. Han, Y.C. Liou, and H. Yu. 2008. Direct interaction of AGL24 and SOC1 integrates flowering signals in Arabidopsis. Development 135:1481-1491.

Ma, L., N. Sun, X. Liu, Y. Jiao, H. Zhao, and X.W. Deng. 2005. Organspecific expression of Arabidopsis genome during development. Plant Physiol. 138:80-91.
Melzer, S., F. Lens, J. Gennen, S. Vanneste, A. Rohde, and T. Beeckman. 2008. Flowering-time genes modulate meristem determinacy and growth form in Arabidopsis thaliana. Nat. Genet. 40:1489-1492.

Messenguy, F. and E. Dubois. 2003. Role of MADS box proteins and their cofactors in combinatorial control of gene expression and cell development. Gene 316:1-21.

Michaels, S.D. and R.M. Amasino. 1999. FLOWERING LOCUS C encodes a novel MADS domain protein that acts as a repressor of flowering. Plant Cell 11:949-956.

Michaels, S.D., G. Ditta, C. Gustafson-Brown, S. Pelaz, M. Yanofsky, and R.M. Amasino. 2003. AGL24 acts as a promoter of flowering in Arabidopsis and is positively regulated by vernalization. Plant $\mathrm{J}$. 33:867-874

Moon, J., S.S. Suh, H. Lee, K.R. Choi, C.B. Hong, N.C. Paek, S.G. Kim, and I. Lee. 2003. The SOC1 MADS-box gene integrates vernalization and gibberellin signals for flowering in Arabidopsis. Plant J. 35:613-623.

Mun, J.H., S.Y. Lee, H.J. Yu, Y.M. Jeong, M.Y. Shin, H. Kim, I. Lee, and S.G. Kim. 2002. Petunia actin-depolymerizing factor is mainly accumulated in vascular tissue and its gene expression is enhanced by the first intron. Gene 292:233-243.

Na, X., B. Jian, W. Yao, C. Wu, W. Hou, B. Jiang, Y. Bi, and T. Han. 2013. Cloning and functional analysis of the flowering gene GMSOC1-like, a putative SUPPRESSOR OF OVEREXPRESSION CO1/AGAMOUS-LIKE 20 (SOC1/AGL20) ortholog in soybean. Plant Cell Rpt. 32:1219-1229.

Nakamura, T., I.J. Song, T. Fukuda, J. Yokoyama, M. Maki, T. Ochiai, T. Kameya, and A. Kanno. 2005. Characterization of TrcMADS1 gene of Trillium camtschatcense (Trilliaceae) reveals functional evolution of the SOC1/TM3-like gene family. J. Plant Res. 118:229-234.

Nakano, Y., H. Kawashima, T. Kinoshita, H. Yoshikawa, and T. Hisamatsu. 2011. Characterization of FLC, SOC1 and FT homologs in Eustoma grandiflorum: Effects of vernalization and post-vernalization conditions on flowering and gene expression. Physiol. Plant. 141: 383-393.

Nam, J., J. Kim, S. Lee, G. An, H. Ma, and M. Nei. 2004. Type I MADS-box genes have experienced faster birth-and-death evolution than type II MADS-box genes in angiosperms. Proc. Natl. Acad. Sci. USA 101:1910-1915.

Nawy, T., J.Y. Lee, J. Colinas, J.Y. Wang, S.C. Thongrod, J.E. Malamy, K. Birnbaum, and P.N. Benfey. 2005. Transcriptional profile of the Arabidopsis root quiescent center. Plant Cell 17:1908-1925.

$\mathrm{Ng}$, M. and M.F. Yanofsky. 2001. Function and evolution of the plant MADS-box gene family. Nat. Rev. Genet. 2:186-195.

Papaefthimiou, D., A. Kapazoglou, and A.S. Tsaftaris. 2012. Cloning and characterization of SOC1 homologs in barley (Hordeum vulgare) and their expression during seed development and in response to vernalization. Physiol. Plant. 146:71-85.

Rhee, S.Y., W. Beavis, T.Z. Berardini, G. Chen, D. Dixon, A. Doyle, M. Garcia-Hernandez, E. Huala, G. Lander, M. Montoya, N. Miller, L.A. Mueller, S. Mundodi, L. Reiser, J. Tacklind, D.C. Weems, Y. Wu, I. Xu, D. Yoo, J. Yoon, and P. Zhang. 2003. The Arabidopsis Information Resource (TAIR): A model organism database providing a centralized, curated gateway to Arabidopsis biology, research materials and community. Nucleic Acids Res. 31:224-228.

Ruokolainen, S., Y.P. Ng, V.A. Albert, P. Elomaa, and T.H. Teeri. 2011. Over-expression of the Gerbera hybrida At-SOC1-like1 gene Gh-SOCl leads to floral organ identity deterioration. Ann. Bot. 107:1491-1499.

Samach, A., H. Onouchi, S.E. Gold, G.S. Ditta, Z. Schwarz-Sommer, M.F. Yanofsky, and G. Coupland. 2000. Distinct roles of $\mathrm{CON}$ STANS target genes in reproductive development of Arabidopsis. Science 288:1613-1616.

Schönrock, N., R. Bouveret, O. Leroy, L. Borghi, C. Köhler, W. Gruissem, and L. Hennig. 2006. Polycomb-group proteins repress the floral activator $A G L 19$ in the $F L C$-independent vernalization pathway. Genes Dev. 20:1667-1678. 
Searle, I., Y. He, F. Turck, C. Vincent, F. Fornara, S. Kröber, R.A. Amasino, and G. Coupland. 2006. The transcription factor FLC confers a flowering response to vernalization by repressing meristem competence and systemic signaling in Arabidopsis. Genes Dev. 20:898-912.

Seo, E., H. Lee, J. Jeon, H. Park, J. Kim, Y.S. Noh, and I. Lee. 2009. Crosstalk between cold response and flowering in Arabidopsis is mediated through the flowering-time gene SOC1 and its upstream negative regulator FLC. Plant Cell 21:3185-3197.

Simpson, G.G. and C. Dean. 2002. Arabidopsis, the Rosetta stone of flowering time? Science 296:285-289.

Sreekantan, L. and M.R. Thomas. 2006. VvFT and VvMADS8, the grapevine homologues of the floral integrators $F T$ and $S O C 1$, have unique expression patterns in grapevine and hasten flowering in Arabidopsis. Funct. Plant Biol. 33:1129-1139.

Srikanth, A. and M. Schmid. 2011. Regulation of flowering time: All roads lead to Rome. Cell. Mol. Life Sci. 68:2013-2037.

Sun, L.D., Q. Zhang, Z. Xu, W. Yang, Y. Guo, J. Lu, H. Pan, T. Cheng, and M. Cai. 2013. Genome-wide DNA polymorphisms in two cultivars of mei (Prunus mume Sieb. et Zucc.). BMC Genet. 14:98.

Tamura, K., D. Peterson, N. Peterson, G. Stecher, M. Nei, and S. Kumar. 2011. MEGA5: Molecular evolutionary genetics analysis using maximum likelihood, evolutionary distance, and maximum parsimony methods. Mol. Biol. Evol. 28:2731-2739.

Tan, F.C. and S.M. Swain. 2007. Functional characterization of $A P 3$, SOC1 and WUS homologues from citrus (Citrus sinensis). Physiol. Plant. 131:481-495.

Thompson, J.D., D.G. Higgins, and T.J. Gibson. 1994. CLUSTAL W: Improving the sensitivity of progressive multiple sequence alignment through sequence weighting, position-specific gap penalties and weight matrix choice. Nucleic Acids Res. 22:46734680.

Valverde, F., A. Mouradov, W. Soppe, D. Ravenscroft, A. Samach, and G. Coupland. 2004. Photoreceptor regulation of CONSTANS protein in photoperiodic flowering. Science 303:1003-1006.

Vandenbussche, M., G. Theissen, Y. Van de Peer, and T. Gerats. 2003. Structural diversification and neo-functionalization during floral MADS-box gene evolution by C-terminal frameshift mutations. Nucleic Acids Res. 31:4401-4409.
Wang, J.W., B. Czech, and D. Weigel. 2009. miR156-regulated SPL transcription factors define an endogenous flowering pathway in Arabidopsis thaliana. Cell 138:738-749.

Wang, T., R. Hao, H. Pan, T. Cheng, and Q. Zhang. 2014. Selection of suitable reference genes for quantitative real-time polymerase chain reaction in Prunus mume during flowering stages and under different abiotic stress conditions. J. Amer. Soc. Hort. Sci. 139:113-122.

Watson, J.M. and E.M. Brill. 2004. Eucalyptus grandis has at least two functional SOC1-like floral activator genes. Funct. Plant Biol. 31:225-234.

Wells, C.E., E. Vendramin, S.J. Tarodo, I. Verde, and D.G. Bielenberg. 2015. A genome-wide analysis of MADS-box genes in peach [Prunus persica (L.) Batsch]. BMC Plant Biol. 15:41.

Wigge, P.A., M.C. Kim, K.E. Jaeger, W. Busch, M. Schmid, J.U. Lohmann, and D. Weigel. 2005. Integration of spatial and temporal information during floral induction in Arabidopsis. Science 309:10561059.

Xu, Z., Q. Zhang, L. Sun, D. Du, T. Cheng, H. Pan, W. Yang, and J. Wang. 2014. Genome-wide identification, characterisation and expression analysis of the MADS-box gene family in Prunus mume. Mol. Genet. Genomics 289:903-920.

Yanovsky, M.J. and S.A. Kay. 2002. Molecular basis of seasonal time measurement in Arabidopsis. Nature 419:308-312.

Yoo, S.K., K.S. Chung, J. Kim, J.H. Lee, S.M. Hong, S.J. Yoo, S.Y. Yoo, J.S. Lee, and J.H. Ahn. 2005. CONSTANS activates SUPPRESSOR OF OVEREXPRESSION OF CONSTANS 1 through FLOWERING LOCUS T to promote flowering in Arabidopsis. Plant Physiol. 139:770-778.

Yu, H., Y. Xu, E.L. Tan, and P.P. Kumar. 2002. AGAMOUS-LIKE 24, a dosage-dependent mediator of the flowering signals. Proc. Natl. Acad. Sci. USA 99:16336-16341.

Zhang, Q.X., W. Chen, L. Sun, F. Zhao, B. Huang, W. Yang, Y. Tao, J. Wang, Z. Yuan, G. Fan, Z. Xing, C. Han, H. Pan, X. Zhong, W. Shi, X. Liang, D. Du, F. Sun, Z. Xu, R. Hao, T. Lv, Y. Lv, Z. Zheng, M. Sun, L. Luo, M. Cai, Y. Gao, J. Wang, Y. Yin, X. Xu, T. Cheng, and J. Wang. 2012. The genome of Prunus mume. Nat. Commun. 3:1318.

Zhong, X., X. Dai, J. Xv, H. Wu, B. Liu, and H. Li. 2012. Cloning and expression analysis of GmGAL1, SOC1 homolog gene in soybean. Mol. Biol. Rpt. 39:6967-6974. 
PmSOC1-1

PmSOC1-2

PmSOC1-3

PaSOC1

PpSOC1

PsSOC1

PySOC1

MdSOC1

ScSOC1

RhSOC1

AtSOC1

CcSOC1

CsSC01

VvSOC1

PTM5

ETL
MVRGKTQMRRIENATSRQVTFSKRRSGLLKKAFELSVLCDAEVALIIFSPRGKLYEFASSSMQTTIERYQKHTKDNLTNN MVRGKIEMKRIENATSRQVTFSKRRNGLLKKAFELSVLCDAQVSVIIFSQKGRLYEFSSSDMQETIKRYHKHAKAGQTN . MVRGKTQMKRIENAASRQVTFSKRRNGLLKKAFELSVLCDAEVALIIFSTRGKLYEFSSSSIGNTLDRYQKRVKDQGLGS MVRGKTQMRRIENATSRQVTFSKRRSGLLKKAFELSVLCDAEVALIIFSPRGKLYEFASSSMQTTIERYQKHTKDNLTNN MVRGKTQMRRIENATSRQVTFSKRRSGLLKKAFELSVLCDAEVALIIFSPRGKLYEFASSSMQTTIERYQKHTKDNHTSN MVRGKTQMRRIENATSRQVTFSKRRSGLLKKAFELSVLCDAEVALIIFSPRGKLYEFASSSMQTTIERYQKHAKDNHTNN MVRGKTQMRRIENATSRQVTFSKRRSGLLKKAFELSVLCDAEVALIIFSPRGKLYEFASSSMQTTIERYQKHTKDNHTNY MVRGKTQMRRIENATSRQVTFSKRRSGLLKKAFELSVLCDAEVSLIIFSPRGKLFEFASSSMQGTIERYQKHAKGNQTSN MVRGKTQMRRIENATSRQVTFSKRRSGLLKKAFELSVLCDAEVALIIFSPRGKLYEFASSSMQTTIERYQKHAKDNQTNN MVRGKTQMRRIENATSRQVTFSKRRSGLLKKAFELSILCDAEVALIIFSPRGKLYEFASNSMQTTIERYEKHTKDNQANN MVRGKTQMKRIENATSRQVTFSKRRNGLLKKAFELSVLCDAEVSLIIFSPKGKLYEFASSNMQDTIDRYLRHTKDRVST . MVRGKTQMRRIENATSRQVTFSKRRNGLLKKAFELSVLCDAEVALIIFSPRSKLYEFASSSMQETIDRYRRHTKDAQPIN MVRGKTQMRRIENATSRQVTFSKRRNGLLKKAFELSVLCDAEVAVIIFSPRGKLSEFASSSMQETIERYLKHTKDTR . . N MVRGKTQMRRIENATSRQVTFSKRRNGLFKKAFELSVLCDAEVALIIFSPRGKLYEFSSSSMQETIERYQRHTKDVHTNN MVRGKTQMRRIENATSRQVTFSKRRNGLLKKAFELSVLCDAEVALIVFSPRGKLYEFASSSMQETIERYRRHVKENNTN. MVRGKTQMKRIENDTSRQVTFSKRRNGLLKKAFELSVLCDAEVALIIFSPRGKLYEFSSSSLCKTIEKYQTRAKDMEA. .

\section{MADS-box}

PmSOC1-1

PmSOC1-2

PmSOC1-3

PaSOC1

PpSOC1

PsSOC1

PySOC1

MdSOC1

ScSOC1

RhSOC1

AtSOC1

CcSOC1

CsSC01

VvSOC1

PTM5

ETL

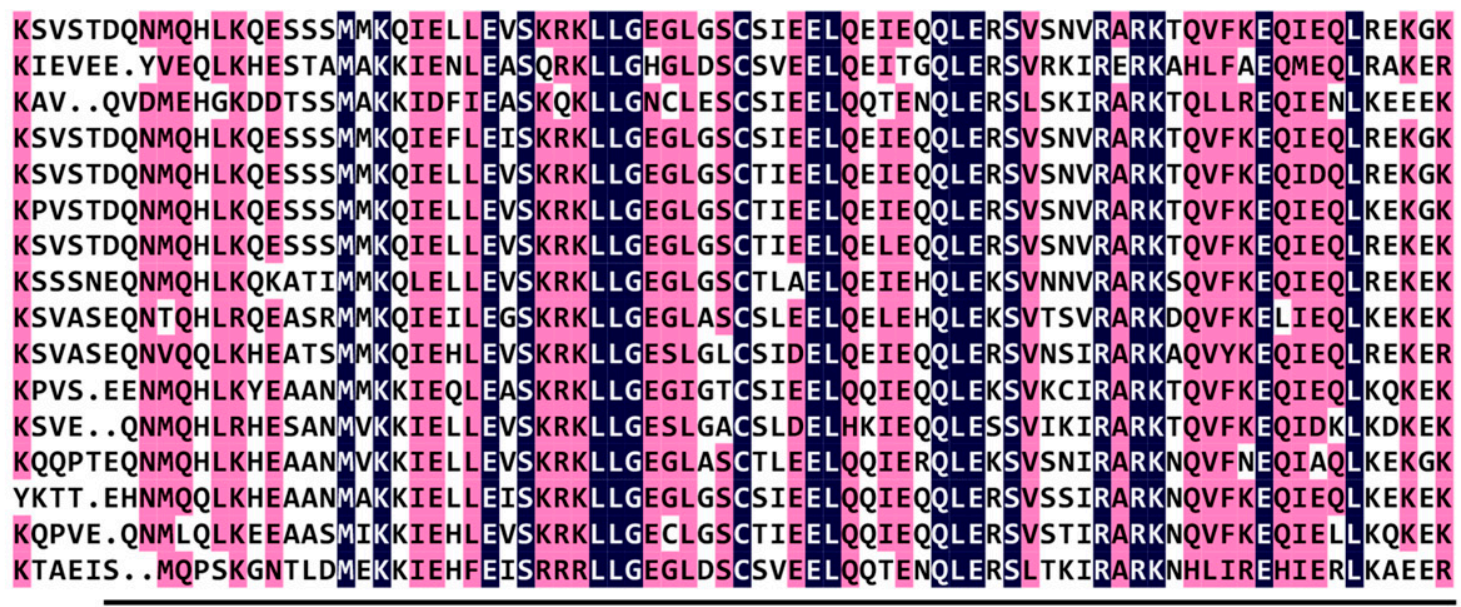

\section{K-box}

PmSOC1-1

PmSOC1-2

PmSOC1-3

PaSOC1

PpSOC1

PSSOC1

PySOC1

MdSOC1

ScSOC1

RhSOC1

AtSOC1

CcSOC1

CsSC01

VvSOC1

PTM5

ETL
214

217

219

214

215

215

216

215

221

215

214

217

219

218

220

205

K-box

SOC1 motif

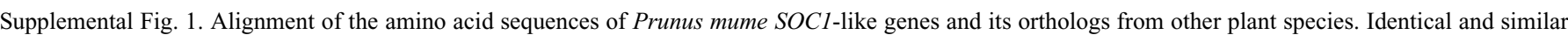
amino acids among predicted protein sequences are shaded in black and gray, respectively. The regions of the MADS domain and K domain are underlined, and the specific SOC1 motif is boxed. The protein sequences included in the analysis have the corresponding protein names as follows: PaSOC1 (Prunus armeniaca), PpSOC1 (Prunus persica), PsSOC1 (Prunus salicina), PySOC1 (Prunus yedoensis), MdSOC1 (Malus domestica), ScSOC1 (Spiraea cantoniensis), RhSOC1 (Rosa hybrida), AtSOC1 (Arabidopsis thaliana), CcSOC1 (Carya cathayensis), CsSOC1 (Citrus sinensis), VvSOC1 (Vitis vinifera), PTM (Populus tremuloides), and ETL (Eucalyptus globulus). 


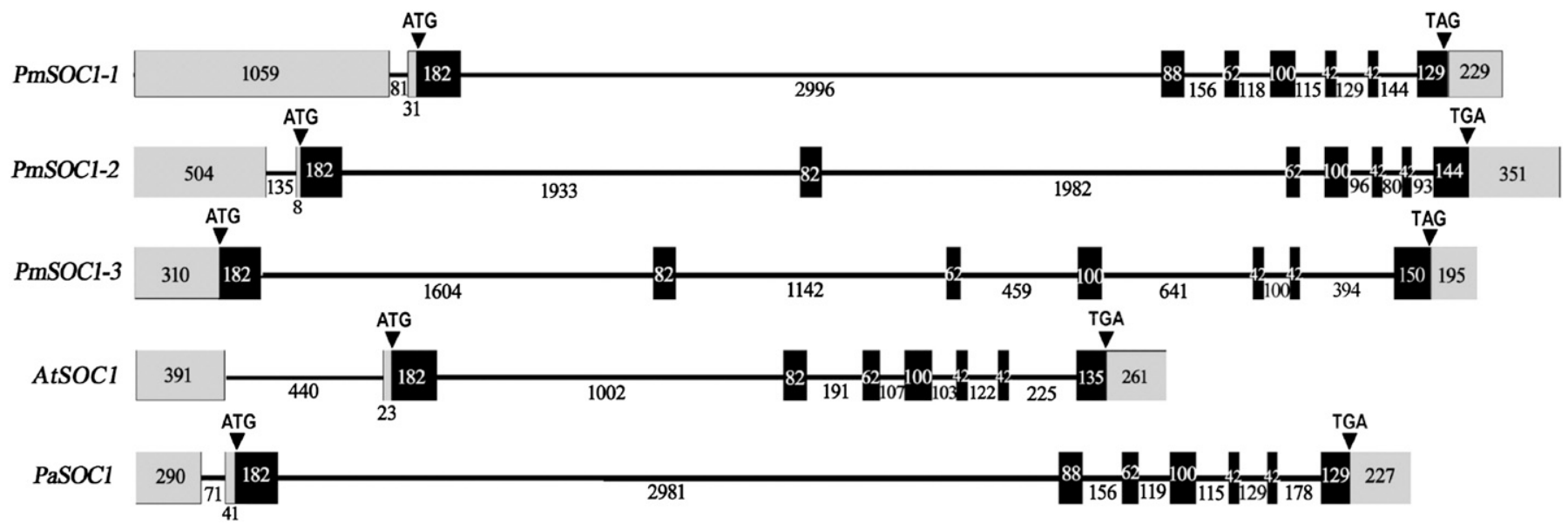

Supplemental Fig. 2. Comparison of sequences and structures of SOC1 homologs. Schematic presentation of intron/exon structure of PmSOC1-like genes compared with its orthologs. Introns are shown as lines and exons as boxes, with the open reading frame in black. Numbers in boxes represent the exon or intron length in base pairs. ATG translation initiation site and TGA/TAG translation stop site are marked. 
Supplemental Table 1. Primers used for clone, quantitative real-time polymerase chain reaction (PCR), vector construction, and reverse transcription PCR (RT-PCR).

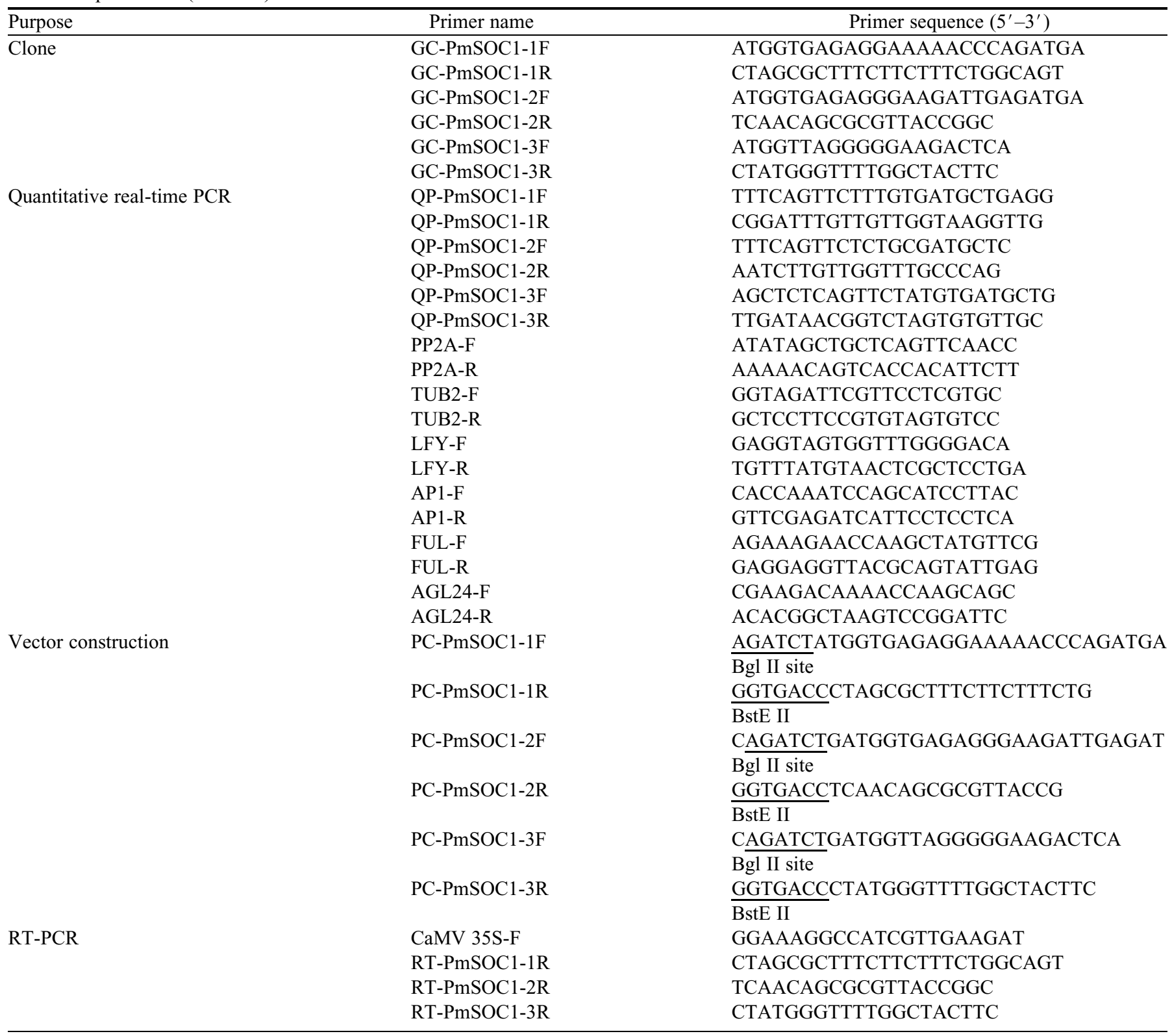

